\title{
Tecnología y sociedad: Impacto de las nuevas tecnologías en la sociedad actual
}

\section{INTRODUCCIÓN}

II. TECNOLOGÍA Y SOCIEDAD: UNA REFLEXION CRÍTICA

1. La justificación del progreso científico: de la "verdad" decimonónica a la "eficacia" de la tecnología operativa. Siglos XIX y XX.

2. Nuevas tecnologías y sociedad: retrato de una influencia

-El desafío educativo.

-El desafío industrial.

3. Caracterización de la tecnología moderna.

-operatividad.

- Impacto social y ecológico.

-Carácter social: realización comunitaria.

-Independencia sobre los individuos y crisis psicológica.

4. Puntos de partida de un planteamiento crítico y reflexivo.

- La falsedad del ideal del "progreso" como realización de las potencialidades del hombre y de la historia a través de la Ciencia y de la Técnica.

- La beligerancia de la ciencia y la tecnología: falsedad de su supuesta neutralidad y autonomía.

-Interacción tecnología-sociedad.

-la cuestión del fin: volviendo a Aristóteles...

III. REFLEXIÓN HISTÓRICO-SISTEMÁTICA SOBRE LA TÉCNICA.

1. La reflexión de los ingenieros sobre la tecnología

-Ernst Kapp

-P.K. Engelmeir y la tecnocracia

-Friedrich Dessauer y la defensa de la creatividad tecnológica.

- La perspectiva analítica y la reflexión de los ingenieros alemanes actuales: Simón Moser, Hans Lenk, Alois Huning, Günter Rophol, Hans Sachsse, Friedrich Rapp. 
2. La reflexión de los filósofos sobre la tecnología

- Lewis Mumford: el mito de la máquina

- José Ortega y Gasset

-Martin Heidegger

\section{CONCLUSIÓN}

1. La crítica del supuesto teoricista de la neutralidad de la ciencia.

2. La evolución de las nociones claves de la ciencia bajo el impacto de las nuevas tecnologías.

3. Las cuestiones éticas y la necesidad de un fin.

\section{INTRODUCC̣IÓN}

En este trabajo nos planteamos, como indica su título ("Ciencia y Técnica: impacto de las nuevas tecnologías en la sociedad actual), una reflexión sobre la interrelación entre ciencia, Técnica y sociedad. Nos motiva a ello un objetivo eminentemente operativo; dilucidar las condiciones bajo las cuales un diseño o proyecto es viable.

El porqué de esta reflexión, indefectiblemente unida a la pregunta por la finalidad y los efectos de la Técnica (sólo se puede juzgar un efecto por referencia a un fin ${ }^{1}$, se nos presenta a cada paso en nuestra vida cotidiana: desde el ordenador de uso particular a los programas de tecnología militar, estamos inmersos en un mundo tecnológico, y los problemas que derivan del uso de la tecnología, así como los horizontes que ésta nos ofrece, nos obligan a reflexionar, desde una base rigurosamente científica, sobre las nuevas tecnologías, sobre el apropiamiento que de las mismas realiza de manera progresiva la sociedad española, y sobre los límites de tal relación.

El afán que nos anima no es exclusivamente especulador: este preguntar por la Técnica no es gratuito; se nos impone, porque necesitamos un criterio para diseñar proyectos tecnológicos, para discernir si la relación coste-eficacia-riesgo favorece una opción u otra... Este criterio no es intrínseco a la

1. "Lo más científico que hay lo constituyen los principios y las causas (...) Evidentemente es preciso adquirir la ciencia de las causas primeras, puesto que decimos que se sabe cuando creemos que se conoce la causa primera. Se distinguen cuatro causas. La primera es la esencia, la forma propia de cada cosa porque lo que hace que una cosa sea, está toda entera en la noción de aquello que ella es; la razón de ser primera es, por tanto, una causa y un principio. La segunda es la materia, el sujeto; la tercera, el principio del movimiento; la cuarta; que corresponde a la precedente, es la causa final de las otras, el bien, porque el bien es el fin de toda producción". ARISTÓTELES, Metafísica, Libro I, sección II. Citamos este texto de todos conocido porque nos ilumina sobre la complejidad de la realidad y porque nos da la clave para juzgar el avance tecnológico: "el bien", un "bien" que, en el caso de la tecnología moderna, no es intrínsece al desarollo de proyectos supuestamente neutrales, sino que es relacional. 
Ciencia: hoy en día no nos planteamos, al elaborar un proyecto, la "verdad" o no del mismo, sino su "efectividad", su "rentabilidad", su "operatividad", su relación con el ecosistema, e interacción dialéctica con la sociedad humana, con la cultura y con las formas de realización del hombre. Evidentemente, estos factores no se deciden por criterios propios de la elaboración científico-Técnica, sino que el juicio positivo o negativo se determina en función de intereses sociales o particulares, sobre los que cabe plantearse su "bondad" inherente... Necesitamos conocer a fondo la estructura y las consecuencias de las tecnologías que aplicamos, para no correr riesgos innecesarios, siendo esa estructura la que nos remite a la sociedad o grupo que la diseña y aplica. El proyecto tecnológico no es neutral ni se justifica a sí mismo, precisamente por ser un fenómeno social. La convicción generalizada que identifica tecnología con progreso es producto de un error de perspectiva, equivocación que analizaremos más adelante.

Buscamos un punto de partida, una base para enjuiciar, un criterio. En nuestra sociedad globalizada, el criterio ha de ser global, no puede ser patrimonio de la matemática ni de la filosofía. Algo no es bueno porque se pueda hacer, sino porque, al situarlo en el punto de interrelación de una multitud de factores, la consecuencia es positiva, no destruye ninguno de esos factores y los potencia. Precisamente es esa conciencia la que provoca la búsqueda de tecnologías "limpias", adecuadas a la estructura social y ambiental, y es esa conciencia la que anima y urge nuestro análisis.

\section{TECNOLOGÍA Y SOCIEDAD: UNA REFLEXIÓN CRITÍCA}

1. La justificación del progreso científico: de la "verdad" decimonónica a la "eficacia" de la tecnología operativa. Siglos XIX y XX.

La ciencia y la Técnica no sólo han crecido en su ámbito de aplicación, en la efectividad de los procedimientos y en la aplicación de los recursos. También ha evolucionado profundamente su status epistemológico, un status que en los últimos siglos ha influido grandemente en otras dimensiones de la cultura, como la filosófica o la artística.

Imaginemos, por un momento, la Royal Society, de la que fueron miembros Hooke y Newton, en lns siglos XVIII y XIX. ¿Cüál era su afán? Pertenece a la cultura popular la reflexión de Newton sobre el carácter de las formulaciones y leyes científicas, $\mathrm{y}$ su frase "Hypotheses non fingo" 2 sirve para ilu-

2. "Newton pretendía resirıigur el contenido de su "filosofía experimental" a enunciados sobre cualidades manifiestas; "teorías" derivadas de estos enunciados e interrogantes que guíen 
minar nuestro camino: en el siglo XVII y XVIII la ciencia moderna se plantea descubrir cómo funciona el universo, cuáles son las leyes que lo rigen. A lo largo de los siglos XVIII y XIX esa "verdad" alcanzada, esa descripción de la realidad, es utilizada para transformar el mundo. Y esa transformación se concibe como buena, porque se basa en esa "verdad" encontrada y se concibe como "verdad encarnada, como "progreso": todos los científicos buscaban la teoría verdadera, y tanto la Ciencia como la Técnica ${ }^{3}$ gozaban de una "neutralidad" derivada de ese afán de verdad. La Ciencia y la Técnica no son buenas ni malas: son verdades necesarias... productos necesarios... del pensar humano, con la capacidad de resolver sus propios conflictos mediante más investigación y más aplicación. No se cuestionaban el salto de la necesidad teórica a la necesidad práctica de una tecnología concreta. La revolución industrial era inevitable... a la noción justificadora de "progreso" se unía la mentalidad liberal del "dejar hacer", con lo que cualquier iniciativa tecnológica campaba por sus respetos sin respetar la sociedad ni la estructura medioambiental de su entorno.

En el mundo de la cultura, el status epistemológico de que gozaba la Ciencia, (su caracterización como búsqueda neutral de una verdad necesaria y de un bien necesario), tuvo su expresión en el positivismo y neopositivismo de principios de siglo. Pero, en la perspectiva teórica, tras la crisis de los fundamentos de la Física (de la mano de la Física cuántica y el principio de indeterminación de Heisenberg), que no de sus realizaciones, cayó por tierra ese ideal. Hoy en día los científicos básicos buscan una caracterización lo más completa posible de la realidad, pero son conscientes de la posible falsedad de lo que enuncian... La puntilla a la idea del progreso basada en el avance de la Ciencia se la dieron dos elementos ajenos al discurso puramente cientifista: la Historia de la Ciencia demostró la sucesión de teorías supuestamente verdaderas y su posterior falsación, así como la relación de dependencia entre cualquier comunidad científica y la sociedad a la que pertenece; las dos guerras mundiales y la tecnología militar (atómica y bacteriológica, principalmente) demostraron la falacia del progreso basado en el mero avance técnico. Si no se orienta y controla, la Ciencia mal entendida y la Técnica mal aplicada pueden devorar a sus propios creadores... La conclu-

\footnotetext{
las investigaciones posteriores. En particular, pretendía excluir las "hipótesis" de la filosofía experimental". LosEE, J., Introducción histórica a la filosofía de la ciencia, Madrid, Alianza Editórial, p. 100.

3. La interpretación habitual de la Técnica como "Ciencia aplicada" es agudamente criticada por numerosos científicos y filósofos, que denuncian el mito de la concepción teoricista de una ciencia desvinculada de la realidad concreta y por lo tanto neutral... En nuestra investigación mantendremos, por el momento, la concepción tradicional.
} 
sión sólo puede ser una: la Ciencia no es neutral, no puede serlo, se desarrolla en una sociedad concreta, puede ser falseada con el tiempo ${ }^{4}$ y sus aplicaciones no son necesarias, ni controlan necesariamente sus efectos, sino que suelen obedecer a criterios económicos y de poder social. La tecnología moderna no es un bien neutral exportable sin más; hay casos concretos en los que resulta muy perjudicial y representa un "retroceso". Un ejemplo concreto lo tenemos en la aplicación de la genética a la agricultura en el Tercer Mundo ${ }^{5}$.

Todo esto nos conduce a plantearnos la pregunta por la Tecnología no desde el patrón de "verdad" (con sus secuelas justificacionistas), sino desde el patrón de "operatividad", de "efectividad", una efectividad que no es "neutral" y sobre la que hay que decidir, partiendo de criterios de eficacia y riesgo que tengan en cuenta las características propias del hombre, sus posibilidades de realización, las circunstancias histórico-sociales, la preservación del ecosistema, la tendencia de los sistemas económicos y de poder a sustituir los intereses del hombre concreto por los suyos propios, etc. El tecnólogo adquiere una nueva dimensión, crítica y ética, que debe guiar su investigación tecnológica. La pavorosa destrucción del medioambiente y la supeditación del individuo a la publicidad creadora de falsas necesidades que perpetúan el sistema nos urgen a desarrollar una propuesta alternativa que parta de la lógica propia del avance tecnológico y de las necesidades humanas. Volvemos a la cuestión del "fin", a la cuestión aristotélica. Nuestra investigación pretende desbrozar parte del camino.

\section{Nuevas tecnologías y sociedad: retrato de una influencia}

Hemos constatado cómo, al entrar en crisis la noción de "verdad" que sostenía el desarrollo de la Ciencia moderna, otros aspectos hasta entonces ocultos han visto la luz, alcanzando los riesgos y fracasos de la tecnología

4. Cfr. KuHN, T.S., La estructura de las revoluciones científicas, Madrid, F.C.E. 1987.

5. "Sólo por consideraciones energéticas, resulta imposible exportar intacta la agricultura mecanizada norteamericana al resto del mundo. Este sistema es el modo de producción alimentaria más caro, en términos energéticos, que jamás se haya empleado. De emplearse para alimentar al mundo entero, absorbería casi el 80 por 100 de consumo energético anual total del globo (...). El desarrollo basado en tecnologías intermedias o apropiadas implica un compromiso con procesos de producción de consumo energético bajo en vez de alto, materiales reciclables en vez de nuevos y recursos renovables, en vez de no renovables. Ejemplo de tecnología apropiada es la utilización de la fuerza de bueyes en lugar de tractores, que está siendo considerada hoy en día como posible alternativa a la tecnificación en la India (...). Este ejemplo sugiere que, en países mal dotados con fuentes de energía industriales, el proceso de desarrollo tendrá que llevarse a cabo, en buena medida, mediante una administración más equitativa y eficiente de las infraestructuras existentes y no mediante la introducción de una base tecnológica nueva". 
moderna el rango de elementos decisivos a la hora de enjuiciar, formular y promover el desarrollo tecnológico, o más bien la imagen que se tiene de él. El avance científico no es un bien en sí mismo: ha de orientarse, y lo hemos de hacer investigando tanto la lógica de las formulaciones tecnológicas como su interacción con el medio natural y social.

Las nuevas tecnologías configuran nuestra sociedad actual; sólo desde ellas es posible elaborar un proyecto continuista o alternativo a las carencias de ésta, y sólo desde las necesidades de la sociedad podemos encauzar el "progreso" tecnológico. Al establecer una relación dialéctica entre ambas, la razón crítica, instancia mediadora y capaz de un juicio equilibrado, vuelve por sus fueros... Es la única alternativa frente a los desafíos que nos plantean tanto la Técnica como la Sociedad contemporáneas. Acerquémonos, pues, a nuestra sociedad tecnológica:

\section{-El desafio educativo}

La incorporación del ordenador, de los medios audio-visuales y de las Técnicas educativas más avanzadas, van creando en los jóvenes (y por consiguiente en el conjunto de la sociedad) una peculiar mentalidad, distinta de la conformada por la educación clásica de los años 50 . Todavía están por estudiar los efectos que produce, en las capacidades del niño, el uso sistemático del ordenador como medio de aprendizaje; junto con los elogios más elevados se oyen voces de alarma que acusan un descenso de imaginación y de actividad creativa en el niño, acostumbrado a pensar en secuencias lineales, esquema característico del ordenador que utiliza como herramienta de aprendizaje: la lógica propia de los sistemas informáticos supone una estructura en la que ha de involucrarse el alumno, imponiendo un proceso lineal de suma y recomposición de datos, a partir de unas claves precisas de información y proceso de datos. El efecto sobre la imaginación, la creatividad y la efectividad, hoy por hoy, no se ha analizado con seriedad desde una perspectiva global, pero hay estudios desesperanzadores sobre aspectos concretos... Esto no quiere decir que la televisión, el vídeo o el ordenador sean instrumentos perjudiciales, sino que está por estudiar el efecto que producen a largo plazo. Pongamos très ejemplos:

1. El conocimiento y, por tanto, la educación y la enseñanza se vertebran cada vez más en torno a las nuevas tecnologías de la información. Por ello, el sistema educativo ha de adaptarse a las potencialidades que ofrecen

HARRIS, M., Introducción a la antropología general, Madrid, Alianza Universidad 1986, pp. 379383. La "promesa" de las "nuevas tecnologías" tiene sus límites, y no podemos ser incautos: en su aplicación prudente nos jugamos nuestra propia supervivencia. 
dichas tecnologías si se quiere que sirva para formar a las personas que han de vivir en un mundo en cambio constante y acelerado. No considerar esta tecnología desde el punto de vista educativo impedirá innovar consciente y planificadamente y hará que se malogre el capital de información científica, Técnica y profesional disponible. Por el contrario, el aprendizaje de y sobre las tecnologías de la información permitirá, desde las primeras etapas escolares, la armonización del proceso educativo. Está en juego el ajuste del sistema educativo con el cambio social en su conjunto ${ }^{6}$.

2. Para poder considerar que el aprendizaje electrónico puede ser efectivo hay que aclarar primero una serie de conceptos excesivamente optimistas (estos medios de aprendizaje se basan en una fuente que irradia luz): 1) concepto: la televisión y las nuevas tecnologías transportan grandes volúmenes de información, pero la mente humana no puede ser confundida con los vehículos de información. Sólo cuando aquélla los requiere pueden éstos producir la información deseada. 2) Concepto: la televisión educativa es superior al maestro que enseña en un aula de forma tradicional. Las experiencias de Somoa y El Salvador arrojaron índices muy por encima de lo deseable de fracaso escolar, se daba un descenso de los rendimientos escolares según se iba introduciendo, puesto que la mayor atención a la acción desarrollada en los programas educativos de la televisión no indicaban una mayor comprensión ni retención. La televisión es un medio básicamente informativo y no cognoscitivo, por ello no puede ser el vehículo fundamental o exclusivo del aprendizaje, aunque sí auxiliar. De todo esto se deduce que las nuevas tecnologías se pueden aplicar en el aprendizaje, pero conociendo y teniendo en cuenta el funcionamiento de la percepción humana ${ }^{7}$.

3. La televisión educativa no consigue contrarrestar la acción perjudicial de la TV de consumo. No hay formas de probar que las generaciones que han crecido con la TV sean más altas, más inteligentes, más maduras o más responsables que sus predecesoras. En 1972, aparece un primer informe sobre TV y violencia y, partir del 78, comienzan a hacerlo estudios, libros y artículos que ponen de relieve la influencia nefasta de este medio en los niños. La TV anula el pensamiento, ya que sólo busca imágenes y sonidos. Disminuye la capacidad de atención y el vocabulario se empobrece hasta niveles de subnormalidad. Los dirigentes de la TV han prescindido de cualquier norma ética. Saben que son un poder y se defienden de las acusaciones con la callada por respuesta. La aparición del vídeo, que en un principio

6. Cfr. Bernal CRuz, F.J., La extensión tecnológica del conocimiento, Ed. Universidad Complutense 1985.

7. EMERY, M., ¿Otra apasionante revolución del aprendizaje? Réplica a C. Kupisiewicz y a M.A. White, Ed. Universidad nacional de Australia 1985. 
parecía la alternativa liberadora ante la tiranía de la TV, no ha conseguido cambiar las cosas. No obstante, la TV sigue siendo, potencialmente, una importante herramienta para los educadores ${ }^{8}$.

¿Qué podemos concluir de estas tres radiografías de la tecnología y la educación contemporánea? Yo creo que la reflexión más importante es la siguiente: no se puede hablar de la tecnología en "abstracto"; lo que tenemos son proyectos tecnológicos concretos, necesarios porque la sociedad no puede prescindir de ellos (como exponíamos en el $\mathrm{n}^{\circ} \mathrm{I}$ ), con unos límites específicos que eliminan toda esperanza soteriológica o mítica en su capacidad de potenciación del hombre (como exponíamos en el $\mathrm{n}^{\circ} \mathrm{II}$ ), y que obedecen a finalidades extra-tecnológicas, ya sean ideológicas o económicas, cuyo "fin", valga la redundancia, no es el crecimiento humano (como exponíamos en el $\left.\mathrm{n}^{\circ} \mathrm{III}\right)$.

El lugar desde el que podemos cuestionar el "progreso tecnológico es precisamente ese supuesto "progreso" en sus encarnaciones concretas: el análisis del mundo de la enseñanza nos revela el carácter relacional y social de la Técnica, y la naturaleza "a-Técnica" de sus fines. Pero no es sólo en este campo: tras los sucesos acaecidos en el siglo $\mathrm{XX}$, todos somos conscientes de que el avance científico no es tal en muchos casos (recordemos la bomba atómica o la guerra bacteriológica), ni es neutral (está al servicio de diversos poderes que lo alientan y financian), ni, por supuesto, es altruista; la importancia fundamental a la hora de decidir la viabilidad o no de un proyecto concreto suele ser la económica..., aunque es discutible si es "económicamente" rentable destrozar el ecosistema. Como pueden ustedes observar, esta última afirmación nos sitúa en un campo distinto al de los proyectos puntuales, en un campo distinto al de la Ciencia y la Técnica: nos sitúan en el campo de la conciencia humana, del proyecto humanizador y de los límites que ha de imponer a sus potencialidades en virtud de sus fines (fines no sólo teóricos, sino de pura supervivencia)... ¿Cuáles son esos fines? Espero que todos estemos de acuerdo en las palabras "paz", "justicia social", "prosperidad", "cultura", "capacidad de comunicación", "creatividad", etc.

En la labor educativa debemos plantearnos tanto la lógica y los límites específicos de las nuevas tecnologías como las necesidades de realización del hombre, para conjugar conscientemente ambos factores, tecnología y humanidad. Nos ubicamos en un horizonte crítico, en el que se ventilan las grandes cuestiones del progreso histórico, un horizonte que parte de la Tecnología y sus aplicaciones, que se vuelve reflexivamente a analizar su origen

8. Cfr. Mallas CaSas, S., Ética y pedagogía c'n el vídeo, Ed. Universidad de Barcelona 1987. 
tecnológico y social, y que a la luz de lo propiamente humano se reorienta en otra dirección. Éste es el gran reto de la sociedad post-industrial: elaborar un planteamiento crítico y realizar propuestas orientadoras. Si nos abandonamos a la dinámica del "avance" tecnológico, debemos ser conscientes de que no nos abandonamos a una "verdad" que se hace realidad en el curso necesario de la historia, sino que nos abandonamos a una dinámica de poder y de dinero que no respeta sino su esencia, el poder y el dinero. Tenemos un ejemplo en la TV: sólo les interesa que se vea y se compre.

\section{-El desafío industrial}

Las nuevas tecnologías son importantes para la industria, y su aplicación efectiva define las posibilidades de progreso y de competitividad de un sistema industrial concreto. Más aún, no sólo dinamiza la actividad productora, sino que modifica sustancialmente el producto, que se ajusta cada vez más a los patrones señalados como óptimos por los agentes tecnológicos.

Pero, precisamente por su gran influencia configuradora, la tecnología nos ofrece un lugar desde el cual acercarnos a la realidad fabril contemporánea, una perspectiva privilegiada desde la que reflexionar sobre sus avances y carencias. El movimiento crítico, reflexivo, autoconsciente que nos anima en este seminario ha de apoyarse en la tecnología para analizar sus límites y el tipo de sociedad que la ha creado y que se recrea a través de ella. Al contemplar este panorama, observamos que el desarrollo industrial actual no está exento de crítica, y que se justifica de forma muy distinta a como lo hacía el crecimiento industrial de los siglos XVIII y XIX: los criterios que dinamizan la actividad productora de nuestros días no obedecen a la "necesidad histórica", ni la industrialización es ya el camino por el que se encarna el "progreso" de la humanidad (ideal justificador de la revolución industrial de los siglos XVIII y XIX). Ya nadie se cree que el "progreso" pueda identificarse con las realizaciones de la industria y la tecnología del siglo XX, ni que el progreso venga de la mano del consumo, de un bienestar sólo material, y sólo materializado tal y como le conviene al sistema (y no sólo con relación a lo material: la compulsión consumista, que se caracteriza por establecer con los objetos producidos una relación de posesión ficticia, instantánea, dependiente siempre de un nuevo mensaje publicitario y de la repetición social (aseguradora) del consumo individual como medio de afirmación personal, invade todas las dimensiones de nuestra vida, incluso las culturales...). A pesar de esto, todos seguimos consumiendo como locos, y dejamos la crítica reflexiva para los locos... Marcuse nos ofreció en su obra "El hombre unidi- 
mensional" un retrato aleccionador de la capacidad integradora del sistema: hasta los críticos acaban por apuntalarlo ${ }^{9}$.

Precisamente la justificación que los ideólogos de la sociedad postmoJerna, o filósofos del "buen vivir", hacen de nuestro sistema de vida, no radica ya en la conciencia de una mayor realización del hombre a través de la Ciencia y la Técnica, la convicción de que ambas son la materialización de un progreso necesario, sino que su argumento fundamental es un argumento de "consumo": apelan al "consumo" como la única forma de vida posible, "sabiduría de la vida" que nos conduce por este fragmentado mundo de objetos que sólo pueden ser poseídos y olvidados ${ }^{10}$, adoptando una postura

9. Sin entrar a discutir los conceptos básicos sobre los que edifica su crítica Marcuse, es interesante resaltar la descripción que realiza de la sociedad contemporánea; en ella descubre dos características fundamentales: "la asimilación de las fuerzas y de los intereses de oposición en un sistema al que se oponían en las etapas anteriores del capitalismo, y la administración y la movilización metódicas de los instintos humanos, lo que hace así socialmente manejables y utilizables a elementos explosivos y "anti-sociales" del inconsciente. El poder de lo negativo, ampliamente incontrolado en los estados anteriores de desarrollo de la sociedad, es dominado y se convierte en un factor de cohesión y de afirmación" MARCusE, H., El hombre unidimensional, trad. A. Elorza, Barcelona, Ariel 1981, p. 7. Analizando la tecnología dentro de la sociedad en la que surge, Marcuse coincide con nosotros en la crítica al supuesto "neutralismo" de la Ciencia y la Técnica: "El análisis está centrado en la sociedad industrial avanzada, en la que el aparato técnico de producción y distribución (con un sector cada vez mayor de automatización) funciona, no como la suma total de meros instrumentos que pueden ser aislados de sus efectos sociales y políticos, sino más bien como un sistema que determina a priori el producto del aparato, tanto como de las operaciones realizadas para servirlo y extenderlo. En esta sociedad, el aparato productivo tiende a hacerse totalitario (...). Ante las características totalitarias de esta sociedad, no puede sostenerse la noción tradicional de la "neutralidad" de la tecnología. La tecnología como tal no puede ser separada del empleo que se hace de ella; la sociedad tecnológica es un sistema de dominación que opera ya en el concepto y construcción de técnicas". Idem, o.c., pp. 25-26.

10. Cfr. TRIAs, E., Filosofía y carnaval, Barcelona, Anagrama 1973, pp. 8-10, y RUBERT DE VENTós, X., Moral y nueva cultura, Madrid, Alianza Editorial 1971, pp. 38ss. En ambos podemos ver una formulación de la ética consumista de la posesión efímera, la falta de identificación, el culto a la velocidad y el cambio, la apuesta por una voraz despersonalización como "solución" (!) de las carencias del hombre. Autores críticos con la postmodernidad "española" ubican este análisis en el contexto social de los 80: "En cualquier caso, este cierto "desencanto refinado" de ciertos voceros de la modernidad se inscribe, mucho más de lo que ellos mismos creen, en un clima de desarrollo material y de bonancismo económico todavía lo suficientemente fuerte entre ciertas clases sociales como para que se produzca el lujo del desencanto ilustrado a que aludimos, más propio de la burguesía que del pueblo. Pero tampoco podría negarse que el propio pueblo, apaleado por la crisis y todo, se mueve en un mismo clima de atenimiento y aceptación de la cultura del "progreso material". Incluso cuando éste se ve frenado (...) no desaparece de la mente (...) aparece como problema, (...), cuya resolución satisfactoria en el fondo se espera para seguir en la brecha, cada vez más lejos", DíAz, C., Sabiduría y locura, Santander, Sal Terrae 1982, p. 40. En definitiva, no cuestionamos la dinámica de nuestra sociedad, sino que nos abandonamos a ella tratando de sobrellevarla lo mejor posible... No cuestionamos la encarnación histórica de la Tecnología y de la sociedad de consumo, sino que identificamos ésta con la noción de verdad y de progreso, aunque esta identificación cada vez nos cuesta más trabajo. El primer paso para poder diseñar una sociedad alternativa y una tecnología alternativa es superar esa identificación que justifica el actual estado de cosas como el único posible. La desespera- 
justificadora del statu quo, justificación que suele acabar en un refuerzo teó rico del sistema...

Sin embargo, cualquier reflexión sobre la sociedad tecno-industrial debe estructurarse en torno. a tres preguntas, que nos ayudan a caracterizar dicha sociedad; la pregunta por la finalidad, la pregunta por los objetivos y la pregunta por el ámbito de aplicación:

-La pregunta por la finalidad; ¿a quién beneficia el "avance"? Recordemos que la revolución informática nace dentro de un esquema social y tiende a apuntalarlo en principio... ¿Cuál es el precio de la cosificación cada vez mayor de la información y de los objetos? La optimización de la producción industrial por medio de las nuevas tecnologías... ¿en qué medida la humaniza? Volvemos a adoptar una inevitable postura crítica: no basta con que se diga que la tecnología es ineludible y nos beneficiará en abstracto. Necesitamos saber cuál es la medida de ese "beneficio", cuál es su dinámica propia, y al contrastarla con la dinámica propia del hombre (o, al menos, con sus carencias contemporáneas), podremos evitar errores autodestructores como los que se dan en la actualidad: contaminación, subnormalización televisiva, etc. El primer problema que se nos plantea es cómo definir ese criterio de humanidad, cuando nuestra "humanidad" se transforma continuamente por medio de la tecnología... Una posible solución sería comenzar la crítica desde nuestras carencias, y establecer su superación como criterio de racionalización y optimización de la tecnología. Sería volver al ideal de progreso decimonónico, pero no a un progreso necesario y dejado a la buena fe de las fuerzas de la sociedad (que a menudo sólo piensan en sí mismas), sino a un afán de "progreso" consciente y orientado hacia el hombre, hacia la creación de un marco favorecedor del encuentro interpersonal, la creatividad, la mejora de nuestros propios afanes, necesidades, ilusiones y carencias. En definitiva, se trata de potenciar la naturaleza humana, y no de consumir más para mantener un sistema que nos ahoga en el tifón publicitario.

-La pregunta por los objetivos: ¿cuáles son los objetivos del progreso tecnológico aplicado a la producción? Cada producto tiene un objetivo específico: "venderse", y un medio de lograrlo: ajustarse a lo que buscan los compradores. Ahora bien, los productos, a través de las campañas de marketing, pueden "educar" las necesidades del comprador, aunque al final no le resuelvan ningún problema. La "no neutralidad" de la tecnología y la influencia de las corporaciones en las necesidades y las compras de los

ción de la postmodernidad y su proclama ética de una vida vacía y vaciada en el consumo tienen su origen en la no superación de esta identificación, con lo cual se quedan sin salida alguna ante las contradicciones de la sociedad, y por tanto se abandonan al lamento. Lamento que, como ya hemos dicho, da solidez al actual estado de cosas. 
gobiernos y sociedades contemporáneas alcanza su expresión más evidente in la gigantesca dimensión de los gastos militares, cuyos objetivos no son, precisamente, la potenciación de la vida humana ${ }^{11}$. Aquí, en los objetivos de la actividad industrial de tecnología puntera, tenemos un caso claro de cómo la operatividad y optimización de los recursos producidos por las nuevas tecnologías se orienta hacia una finalidad definida por criterios socio-políticos y de poder..., que no funcionan buscando un hombre mejor, sino buscando otros objetivos propios de su dinámica y al servicio de los cuales subordinan todo lo demás.

Pero no sólo en el campo militar debemos preguntarnos por objetivos... ¿Qué pasa en la sociedad civil de consumo masivo? El objetivo es consumir, lograr que se compre, aun a costa de instaurar una lógica de compulsión y de dominación, porque se busca "tener" para afirmarse socialmente por tal "tener" (aunque algunos busquen comodidad de vida y otros busquen la prepotencia sobre los demás mediante tal afirmación). La búsqueda de lo básico para vivir, tal y como lo define la sociedad de consumo, nos ata sin darnos cuenta cada vez más, y cada vez más gente no tiene lo esencial para sobrevivir (recordemos el Tercer Mundo), mientras nosotros no alcanzamos nunca un estado satisfactorio porque el afán consumista es insaciable. ¿Consecuencia? Una compulsión y una neurosis social generalizada, así como una afirmación social mediante "objetos" de consumo que reduce nuestra capacidad de ser sujetos de la Historia y de nuestra propia intimidad histórica...

—La pregunta por los ámbitos de aplicación: la tecnología y la industria tecnológica no es aplicable de igual manera a cada país y a cada estructura social concreta. El criterio de aplicación no puede formularse en torno a lo más avanzado tecnológicamente, sino en relación a lo más apropiado en base a los recursos materiales y humanos, y la estructura sociocultural. "Hay quienes consideran que toda novedad tecnológica, por el hecho de serlo, es un

11. Un extremo en el que quedan patentes los objetivos exterminadores de la tecnología militar, que investiga en la perspectiva de optimizar la máxima "destruye pero no te dejes destruir", es de la guerra química. Lo que hace ideal este armamento es su capacidad de destrucción, "ideal" que no creo pueda definirse como encarnación del "progreso" de la humanidad; como ejemplo, citemos la reflexión de un analista militar español: "También es previsible un aumento espectacular de Ejércitos que en un próximo futuro accedan a la posesión de los agresivos $\mathrm{B}$ y $\mathrm{Q}$, sobre todo de países medianamente industrializados que dispongan de una aceptable industria farmacéutica y de fermentación, ya que la fabricación y elaboración de éstos no precisa de grandes esfuerzos tecnológicos ni industriales. Los últimos acontecimientos bélicos (Afganistán, Irán e Irak) confirman esta presunción y además no debemos olvidar que los agresivos B y Q dejan intacto el potencial económico (...) lo cual los hace ideales para su utilización dado el perfil logístico que conllevan" Díaz rodríguez, M. SOla FERnández,. S., Redondo FRÍAS, Un reto asumido: la defensa NBQ en España, en "Defensa", n 136-137, Madrid 1989, p. 13. El ejemplo militar constituye la mayor prueba de la no neutralidad de la tecnología. 
paso más en la senda del progreso. "Innovar" y "mejorar" se usan con muchísima frecuencia como sinónimos" ${ }^{12}$. Pero no es así. En diversos ejemplos de aplicación de la tecnología genética a la agricultura del Tercer Mundo observamos cómo no es aplicable la tecnología punta, y cómo las tecnologías alternativas ofrecen una solución adecuada y favorecedora de la calidad de vida; estos episodios rompen la autojustificación del avance tecnológico como progreso en sí, remitiéndonos a las preguntas iniciales por los objetivos y los fines, de cara a la consecución de un ritmo de vida que otorgue al hombre más posibilidades de ser "humano".

\section{Caracterización de la tecnología moderna \\ Operatividad}

El concepto clave que caracteriza, justifica y define la tecnología moderna es el de "operatividad". La tecnología, a diferencia de la Ciencia teórica, es un saber operativo, que surge de las necesidades de la realidad y que vuelve a ella dispuesta a transformarla, articulándose en torno a criterios de eficacia y control. Su crecimiento atiende a las exigencias de esa actuación operativa que se le exige y de la que surge, por lo que hemos de buscar la motivación tecnológica en ese entramado entre la realidad, las exigencias del hombre y el conocimiento teórico-práctico. El criterio para juzgar su adecuación no es ya el puro afán por la "Verdad", sino la operatividad del diseño tecnológico.... La postura ética del tecnólogo se fundamenta en el patrón de operatividad y eficacia, y difiere según se conciban éstos y sus objetivos. La tecnología es Ciencia operativa por su propia naturaleza, y precisamente al enfrentarse con los problemas prácticos adopta un doble criterio: eficacia del proyecto, y control del proceso y de las consecuencias.

\section{-Impacto social y ecológico:}

Que la sociedad tecnológica ha evolucionado en los dos últimos siglos más que en los diez anteriores es un hecho ${ }^{13}$. El ritmo de cambio es cada día más acelerado y persistente; las nuevas tecnologías producen cambios más

12. SAnMARTIN, J., No toda producción es sintesis. Reflexiones en torno a las diferencias entre tecnologías de control y tecnologías sintéticas, en "Anthropos", n 94-95, Barcelona 1989, p. 40.

13. Es importante señalar que el progreso tecnológico ha de medirse por la escala propia de la tecnología operativa, y así tendremos progreso "operativo", pero no necesariamente de otro tipo. Al constatar el carácter propio del progreso "tecnológico", observamos cómo tal progreso no es absoluto ni afecta de igual modo a los distintos órdenes de la vida humana. En relación a esta vida humana hemos de juzgarlo, situándolo en un contexto social, con la convicción (producida por el análisis de las características de la tecnología) de que no se pueden identificar progreso "tecnológico" y progreso "humano". A su vez, la operatividad tecnológica nos da una clave para comprender la naturaleza del hombre actual. 
rápidos y profundos en las formas de vida que experimentan su impacto. pudiendo llegar a afectar las condiciones mismas de la vida (recordemos la listrucción de la capa de ozono por los CFCs y sus consecuencias). Éste es el gran riesgo y lo que define a la ingeniería genética, o a la tecnología nuclear, en relación a las Técnicas de producción anteriores al siglo XIX. Al afectar a la sociedad en la que se desarrolla y aplica, no sólo influyen en las características de la misma, sino que configuran de un modo distinto las relaciones de producción y las formas de trabajo: "los desarrollos tecnológicos en su aplicación industrial han generado formas de trabajo cada vez más altamente maquinales y jerarquizadas" ${ }^{14}$. Pero el impacto de las nuevas tecnologías no afecta sólo al ritmo de cambio socio-histórico y la configuración concreta de la sociedad (estructuras de producción, de intercomunicación, etc.); también afecta a los objetos producidos: la artificialidad, la civilización del plástico y los materiales sintéticos, se caracteriza por la suplantación de la naturaleza por productos de la tecnología. Este cambio de los objetos producidos tiene unas ventajas y riesgos específicos, por cuanto el individuo se ve rodeado de objetos artificiales, sin conexión natural alguna con él, y absolutamente incomprensibles (en cuanto que la complejidad tecnológica de los objetos nos lleva a usarlos pero a no entenderlos, a necesitar un "técnico" que los arregle, con lo cual vivimos en mundo extraño, que sólo podemos comprar, y ante el que no podemos hacer nada...).

¿Cuál es la reacción de la sociedad ante los impactos tanto ambientales como sociales de las nuevas tecnologías? "La necesidad de asumir los impactos de los desarrollos tecnológicos ha pasado, al menos, por tres fases. La primera (...) se aceptaban como intrínsecos al proceso tecnológico. Y, por tanto, no se pensaba en la necesidad de evitarlos (...). En la segunda, en la que se hallan inmersos la mayor parte de los países industrializados todavía, los impactos tratan de ser minimizados mediante la introducción de medidas de control. Un control (se supone generalmente) realizable mediante la introducción de las correcciones pertinentes en el diseño tecnológico especial. Por las expresiones empleadas debe resultar claro que el control es algo que se hace después, no antes de llevar a cabo una aplicación tecnológica (...). En la tercera, (...) los impactos tratan de conocerse lo más posible y remediarse antes (...). A este respecto viene poniéndose énfasis (y dinero) en la mejora de la metodología de evaluación de impactos" ${ }^{15}$.

Como podemos observar, en las tres posturas que señala J. Sanmartín nunca se cuestiona el carácter ineludible del progreso tecnológico. Y en cual-

14. SAnmartín, J., o.c., p. 42

15. Idem, o.c., p. 41. 
quier caso, el elemento decisorio es la rentabilidad: todo control debe hacerse, pero debe proporcionar beneficios económicos. Ahora bien, ¿hasta qui punto se evalúan con criterios de rentabilidad la preservación del ecosistema? Es un problema "abierto", y a medida que la contaminación vaya poniendo en peligro nuestra propia vida, el criterio de rentabilidad irá perdiendo fuerza en relación al criterio de supervivencia. Aunque, desgraciadamente, no parece que hoy por hoy exista en la mente de los que diseñan y efectúan proyectos tecnológicos una alternativa seria al criterio "monetario".

Sin embargo, la estimación de los impactos de las nuevas tecnologías sobre una base meramente económica es un "engaño", porque no es solamente la base económica la que resulta afectada: los impactos de la tecnología afectan a nuestra forma de vida y posibilidades de supervivencia..., dándose casos en los que la variable económica y el cálculo de benéficos no deben ser los factores principales al juzgar un proyecto (por ejemplo, la destrucción de los bosques tropicales, la eliminación de tecnologías dañinas como las plantas de producción de abesto, etc.). En relación a esta cuestión, hemos de señalar cómo el análisis de los impactos se suele reducir al ecosistema, sin tener en cuenta el impacto social de las nuevas tecnologías, impacto muy superior al realizado en el medio-ambiente en casos como el de la tecnología de la información. Únicamente a nivel educativo, como antes indicábamos, se produce una reflexión incipiente sobre este tema.

\section{-Carácter social: realización comunitaria}

El presupuesto de la "neutralidad" de la Ciencia y de la Tecnología, y la supuesta encarnación del "progreso histórico" que representan ha quedado roto al comprobarse, tras la revolución realizada en la Historia de la Ciencia por Kuhn, que los científicos realizan su actividad en comunidades científicas, aceptando paradigmas compartidos y orientando su investigación hacia aquellos objetivos que su sociedad les marca, bien a través de las necesidades tecnológicas, bien a través de orientaciones propias de la mentalidad de la comunidad de científicos y de la comunidad social más amplia en la que se incardinan. El científico no investiga movido por un afán puramente teórico, idealista, de búsqueda de una verdad absoluta y definitiva: la Historia de la Ciencia nos enseña cómo las verdades que se alcanzan son relativas, y cómo intervienen otros factores distintos en la actividad científica. En definitiva, gracias a estas recientes investigaciones situamos la Ciencia y la Técnica en su lugar apropiado: en una sociedad concreta, de la que surgen y a la que transforman. De aquí que debamos contrastar el avance científico técnico con las necesidades de la sociedad y con sus carencias, sabiendo que la única 
justificación de la Técnica moderna es la mejora de la vida humana, no el avance por el avance o el avance motivado por motivos distintos a esa realización del hombre, objetivo último de cada uno y de la sociedad, y fundamento desde el cual criticar y exigir a la sociedad, al estado y a la Ciencia tecnológica.

A partir de estos datos, podemos reseñar dos ideas muy importantes; en primer lugar, la no neutralidad de la Ciencia, manifestada por otra parte en casos como la bomba atómica (tecnología aplicada) o el de Lysenko (Ciencia teórica). En segundo lugar, la relatividad del avance científico, cuyas grandes verdades han sido negadas en el transcurso de los siglos, problemática de moda a causa de la disputa entre Hawking y Yakir Aharanov ${ }^{16}$.

Al situar la Tecnología en un entramado socio-económico y político, la cuestión de la finalidad y de los objetivos de los proyectos tecnológicos nos obliga a plantearnos la finalidad y objetivos de la sociedad, de la estructura socioeconómica que orienta el progreso tecnológico y del proceso dialéctico de interacción entre sociedad y tecnología, ya que éste, al cumplir los objetivos marcados por aquélla, la transforma a su vez. La motivación profunda de nuestro análisis se origina en este dato: la tecnología es un producto que define, configura y refleja la sociedad ${ }^{17}$, y a partir de ella hemos de enfrentarnos con la estructura social y económica, con las espectativas de crecimiento y realización de los hombres, etc. Al analizar la tecnología (en Estados Unidos, Japón o la Unión Soviética) no podemos olvidar su inserción en una comunidad social y la influencia que ésta ejerce en aquella.

\section{-Independencia sobre los individuos y crisis psicológica}

Tanto la estructura social como el estado de las sociedades contemporáneas se caracterizan por su gran complejidad y articulación, lo que produce el efecto de una despersonalización, delegación de responsabilidad en el Estado y crisis de la identidad social e individual; en definitiva, una sociedad en la que el individuo se encuentra solo y vendido frente a los montajes

16. Yakir Aharonov "ha declarado recientemente en Madrid que, tras la revolución cuántica y la teoría de la relatividad, la próxima gran convulsión que la física contemporánea va a conocer será la revolución de nuestro concepto de tiempo. Después de varios siglos de concepción lineal y progresiva del tiempo, parece que entraremos en una nueva concepción de esa categoría que, como el espacio, constituye el asidero del hombre en el mundo. Es algo que se venía anunciando desde principios de este siglo, y no tanto en la física como en la poesía y en la filosofía (basta con pensar a este respecto en Heidegger). Es muy conocido el díptico de Hölderlin: 'lo que permanece / lo fundan los poetas'. Lo que permanece y lo que cambia" Ovidio, El tiempo en ABC, Domingo 29-10-89, Madrid, p. 20.

17. "La tecnología actual expresa con hondura y radicalidad el verdadero porvenir y la naturaleza de la sociedad" Editorial, La tecnología actual, un nuevo y radical proyecto metafísico, en Anthropos, Revista de documentación gráfica de la cultura, n 94-95, Barcelona 1989, p. 3. 
publicitarios y la estructura burocrática ${ }^{18}$. A su vez, los mecanismos de identificación social se vertebran en torno al consumo, con lo que las posibilidades de una comunicación mayor, de una vivencia culturalmente diferenciada del fenómeno publicitario (y, por lo tanto, con más capacidad de ser crítica) se reducen. Es en esta sociedad en la que se instauran las nuevas tecnologías.

Aunque existen diversas posturas desde las que se valora la relación hombre-Técnica, es cierto que la tecnología (producto de una sociedad tremendamente estructurada) crea una serie de condiciones que provocan en nosotros exigencias y necesidades de las que no podemos desentendernos, sin las que la existencia cotidiana es imposible. Al mismo tiempo, dada la complejidad del desarrollo tecnológico, nos servimos de objetos tecnológicos y de sus efectos, pero queda fuera de nuestro alcance la comprensión de los procesos que permiten obtener esos "efectos": vivimos cada vez en un mundo más extraño y distante; nuestra lavadora puede llegar a ser un misterio absolutamente inaccesible, con lo que nuestra capacidad de identificación con los productos de nuestra sociedad se resquebraja, resquebrajándose al unísono nuestra capacidad de comprensión y fruición de la existencia. En este medio ambiente el ordenador personal nos otorga un "poder" peculiar, ya que nos permite acceder a fuentes de información, elaborar programas, etc. Sin embargo, no es oro todo lo que reluce; también tiene sus riesgos: "(...) se ha podido comprobar que la relación con el ordenador en vez de con un sujeto humano específico genera efectos de poder específicos e induce a conductas de mayor sumisión que van a suponer un cambio en las relaciones sociales interpersonales" ${ }^{19}$. En definitiva, la crisis de soledad individual, desarraigo, y la dependencia psicológica de los objetos tecnológicos conducen, si sólo nos guiamos por el ideal de consumo y la efectividad, a un callejón sin salida, ya que el hombre proyecta en ambos fenómenos (consumo y eficacia) una serie de necesidades básicas (comunicación interpersonal, satisfacción en el trabajo, identificación con los productos de su trabajo y con la sociedad, etc.), necesidades que en dicha dinámica se frustran, tendiendo a producir una conducta más compulsiva y con un mayor nivel de dependencia (ya que el sistema sólo nos da una oportunidad: consumir más, producir más, identificarnos más con los mensajes publicitarios y la estructura significativa y motivacional de la lógica consumista y del aparato tecnológico). Detengámonos un momento en el análisis de las consecuencias que producen en la

18. López PelÁEz, A., El Estado: acercamiento a la sociedad actual, en "Estudio Agustiniano", vol. XXI, Valladolid 1986, p. 636.

19. GARCíA-Merita, M.L., Tecnología y naturaleza humana, en "Anthropos", Revista de documentación científica de cultura, nº 94-95, Barcelona 1989, p. 112. 
cultura y en el psiquismo del hombre la implantación de las nuevas tecnologías en el campo del trabajo y del ocio:

-Características del trabajo tecnificado:

"Tengamos en cuenta que el hombre moderno no trabaja para cumplir unas necesidades biológicas, no tiene acceso directo a las cosas. Trabaja para un mercado o unos clientes que le son ajenos y tiende a acceder a la representación de las cosas en vez de a las cosas mismas. El hombre moderno está cada vez más alejado de su trabajo, la pérdida de iniciativa y participación es cada vez mayor y se ha aumentado excesivamente la actividad mental en detrimento de la Física" 20.

-Influencia en las relaciones sociales:

"(...) la tecnología cotidiana tiende a desarrollar la soledad y elimina el establecimiento de contactos interpersonales. Así, por ejemplo, el teléfono nos exime de encuentros personales, la televisión elimina las conversaciones familiares y nos aísla en nuestros hogares, los cajeros automáticos nos evitan el contacto con otro ser humano, de igual forma que el magnetófono, el télex y tantos otros objetos tecnológicos que están haciendo de nosotros una colección de individuos sin interacciones que, incluso, como señala Lipovetsky, excluye toda posibilidad de cultura" ${ }^{21}$.

-El problema de la jubilación y el tiempo libre:

"El alejamiento de la vida profesional, tanto de los jubilados como de los desempleados jóvenes, supone algo más que el cese de una actividad. Implica, también, la adopción de un nuevo rol, una reestructuración del campo social y, asimismo, supone generalmente, fuertes repercusiones en la economía personal y un desplazamiento de los intereses personales del mundo del trabajo al del tiempo libre, para el que el ser humano, nacido en esta era tecnificada y de culto a la ejecución y la productividad, no está preparado. Además, paradójicamente, el hombre moderno no tiene más "tiempo", ni para él, ni para la familia, ni para los amigos. Así pues, pasa sus problemas en solitario, en medio de una multitud urbana indiferente que le hace sentirse cada vez menos individualizado" 22 .

-Repercusiones en el psiquismo humano:

"(...), la soledad y aislamiento al que el ser humano está sometido, el alejamiento del trabajo, la monotonía del mismo, la falta de tiempo, la amenaza

20. Idem, o.c., p. 112.

21. Idem, o.c., p. 112.

22. Idem, o.c., p. 112. 
del desempleo y el cansancio biológico, junto a la tremenda dependencia di los objetos tecnológicos, son consecuencias de esta era tecnológica qu repercuten muy negativamente en la salud psíquica del hombre moderno. Efectivamente, todas estas circunstancias lo angustian, lo desconciertan y lo sumen en la incertidumbre patologizante que lo esclaviza, en lugar de darle esa libertad que parecían ofrecerle los tremendos progresos tecnológicos del mundo moderno. Estas graves repercusiones en la esfera psíquica del ser humano pueden detectarse de diversas maneras, por una parte por el aumento de la incidencia de los trastornos psíquicos de la población general y por otra por la aparición de nuevas formas de enfermar que parecen ser características de nuestra época. (...) depresiones, (...) neurosis, (...) cansancio de la vida, (...) angustia existencial, (...) stress continuado, (...) depresiones de claudicación, (...) enfermedades psicosomáticas, (...) pérdida de creatividad, (...) drogadicción, (...) . Éstas son las características psicológicas que ha conseguido instaurar en el hombre el proceso tecnológico de nuestra civilización. En consecuencia, podríamos afirmar que la tecnología se ha adueñado del ser humano y está modificando su auténtica naturaleza a una velocidad que él no puede asimilar impidiendo, por tanto, sus posibilidades de adaptación" 23 .

El estudio de M.L. García-Merita es desalentador respecto al futuro del hombre tecnológico. El problema mayor de este tipo de análisis es la caracterización de la Técnica como algo que nos es dado, que se sobrepone a nosotros, como un ser en sí que nos oprime, en definitiva, la "reificación" de la Técnica. Naturalmente, la Técnica es producto de una sociedad, y, aunque la configura de manera determinante, son las estructuras sociales, la dinámica del consumo y la economía actual, los causantes de su aparición, y la crítica a la tecnología sólo tendrá efecto en la medida en que remita a la sociedad y a las estructuras socio-económicas y de poder que la alientan. Por otra parte, este análisis efectúa un golpe decisivo a la teoría de la neutralidad de la Ciencia y la Técnica, y a la concepción de sus avances como productos del progreso de la Historia, y por lo tanto inevitables, argumentación tras la cual se escudan proyectos decididamente peligrosos y destructivos, como los ensayos de tecnologías nucleares, así como experimentaciones de todo tipo, así como se presenta la sociedad de consumo como la única posible, con lo que se elimina de raíz el pensamiento crítico respecto a lo fundamental, la configuración de la sociedad tecnológica actual. La implantación de las nuevas tecnologías conlleva unos riesgos específicos que hay que controlar antes de la realización práctica de los proyectos. Y son los problemas causados por

23. Idem, o.c., pp. 112-114. 
la sociedad tecnológica el lugar adecuado para buscar una caracterización de las necesidades del hombre y de los límites de la realización que los individuos pueden conseguir a través de la tecnología moderna. Estas necesidades deben ser el motor de nuestras críticas y la clave fundamentadora de nuestra ética para una sociedad tecnológica. En definitiva, se trata de ser críticos en la sociedad y la técnica contemporánea para poder ser dueños de las mismas, para ser sujetos de nuestra propia vida y de nuestra propia historia.

\section{Puntos de partida de un planteamiento crítico y reflexivo}

La complejidad del progreso tecnológico, sus implicaciones, los fines a que obedece (determinados por la comunidad científica y la sociedad en que se desarrolla), y los efectos que provocan, suponen una dimensión de responsabilidad social de los científicos ante la que no valen excusas ni buenas palabras. Ineludiblemente hemos de plantearnos, a partir del análisis crítico de la tecnología, cómo resolver los problemas y cómo encauzar los extravíos de la razón tecnológica. Científicos y tecnólogos tienen en esta tarea social un papel preponderante, porque sólo desde la Ciencia y la Técnica moderna podemos superar estos problemas..., aunque también hay que decir que sólo podemos obtener una respuesta positiva analizando todos los factores extracientíficos que guían el desarrollo científico-tecnológico: argumentaciones económicas, militares, políticas, o de cualquier otro signo. Bajo mi punto de vista, tanto lo científico como lo extra-científico debe estar orientado a superar las carencias psico-socio-económicas del hombre concreto; es a este hombre al que se le plantea la Técnica como gigantesco problema ${ }^{24}$.

La fuerza de nuestro discurso se apoya en la crítica a los mitos que, basados en el ideal de progreso y en el concepto de verdad (búsqueda de la Verdad), justificaban la Ciencia y la Técnica como un bien en sí mismo, encarnación inevitable de la historia. Ya hemos comprobado cómo la Técnica no es neutral, y por lo tanto cómo sus realizaciones concretas no se pueden aceptar sin más. ¿Cuáles son los puntos de partida de cualquier análisis sobre la tecnología operativa contemporánea?

- La falsedad del ideal del "progreso". como realización de las potencialidades del hombre y de la historia a través de la Ciencia y la Técnica:

El progreso humano no viene dado por el progreso "tecnológico" sin

24. "De donde resulta que al hombre medio se le ha hecho hoy su propia vida menos transparente que lo que la suya era al hombre en otros tiempos. La técnica, cuya misión es resolverle al hombre problemas se ha convertido de pronto en un nuevo y gigantesco problema" ORTEGA Y GASSET, J., Meditación de la técnica y otros ensayos sobre ciencia y filosofía, Madrid, Alianza Editorial 1982, p. 17. 
más, y aún es discutible que tal "progreso" sea el "progreso" con mayúsculas...., en sentido profundo, porque, frente a tantas carencias de la humanidad...., ¿es "progreso" la velocidad punta de 250 kilómetros en un tren o en un coche?, ¿es "progresar" implantar unas tecnologías que potencian la riqueza de los países ricos y son imposibles de financiar por los países pobres? ${ }^{25}$. ¿Es "progreso" una tecnología de la información que nos supedita a los intereses de consumo y poder de una sociedad dada mediante la publicidad? Si estimamos el "progreso" como una "realización" de las potencialidades del hombre, nuestra tecnología operativa se hace merecedora de una fortísima crítica, sobre todo por cuanto su objetivo y el afán que la mueve (que mueve los diseños tecnológicos) no es dicha "potenciación", sino las escalas de venta, efectividad y poder de la sociedad de consumo occidental o de la sociedad cerrada, dogmática, de los países del Este. ¿Dónde está el hombre? ¿Dónde está el progreso? Tenemos ejemplos, en el siglo XX, que nos muestran la "calidad". del progreso alcanzado: guerras mundiales, guerras locales, armas nucleares, armas químicas, el hambre y la pobreza del Tercer mundo, etc. Urge recuperar una capacidad crítica, una finalidad dirigida a la persona, en esta sociedad guiada por el criterio del mantenimiento del sistema.

-La beligerancia de la Ciencia y la Tecnología: falsedad de su supuesta neutralidad y autonomía

Consecuencia de lo anterior, y de los modernos estudios sobre Historia de la Ciencia, es la afirmación de la no-neutralidad de la Ciencia y sus proyectos operativos: el científico y el tecnólogo no están más allá del bien y del mal, luchando por una verdad pura: a menudo luchan por cumplir objetivos diseñados por una necesidad de mercado o por una prioridad bélica o de otro tipo.

Al analizar la moderna sociedad tecnológica, no podemos dar un cheque en blanco a sus diseños: hay que contrastarlos con su contexto socio-económico, para poder encauzarlos hacia una finalidad auténticamente humana ${ }^{26}$.

25. En la reciente conferencia internacional contra la destrucción del medio-ambiente quedó claro cómo los países ricos no estaban dispuestos a financiar tecnologías "limpias" en los países del Tercer Mundo, y como éstos carecían de los medios económicos suficientes para financiarlas por sí mismos, dado que son más caras y que han de ser importadas de los países ricos.

26. No pretendo caer en la ingenuidad de buscar un "criterio", el "criterio", para juzgar lo tecnológico en una época en la que hasta el concepto de naturaleza humana está en profunda crisis, y nos situamos en la pérdida de la identidad del hombre como punto de partida pará enfrentarnos a la realidad... Ahora bien, nuestra crítica, necesaria para que el sistema no nos gane la partida, puede comenzar por señalar los límites y las posibilidades de lo tecnológico, y, a pesar de las ambivalencias que todo juicio sobre los efectos de la técnica conlleva (a éste le va bien, a éste otro le va mal...), no podemos cejar en el empeño: tenemos la obligación de buscar 
En caso contrario, (a sabiendas de la dificultad de definir lo "humano", o de encontrar un criterio cartesiano para discernir lo que se ajusta a la naturaleza del hombre de lo que le perjudica), correremos el riesgo señalado por J. Robinett: "Cualquier observador casual de los seres humanos y su tecnología podría fácilmente notar que primero fabricamos y luego consideramos las consecuencias. $\mathrm{El}$ homo faber tiende a guiar al homo sapiens. $\mathrm{El}$ siglo $\mathrm{XX}$ está preñado de vívidas ilustraciones de esto, y todos estamos obligados a vivir con las consecuencias no previstas por los arquitectos originales de tecnologías que aunque pueden enriquecer nuestras vidas, también la amenazan" 27 .

\section{-Interacción, tecnología-sociedad}

Hoy en día ya no se puede mantener la tradición renacentista que veía al hombre como dueño y señor de sus actos y actuaciones... La dialéctica hombre-Técnica es una dialéctica entre iguales, y, si acaso, la Técnica lleva todas las de ganar. Por de pronto, está configurando un nuevo mundo y un nuevo hombre radicalmente distinto del anterior. Pero tampoco se puede caer en la tentación de "reificar" la Técnica, convirtiéndola en una especie de encarnación del destino o de la necesidad. Podemos actuar todavía desde dentro de la sociedad tecnológica y con un fin independiente de la lógica del sistema de producción, del sistema de poder, o del propio sistema tecnológico; podemos luchar por construir un mundo diferente, más humano: el reino del hombre es la actuación (característica principal de la Técnica). El mañana no está escrito, y la "necesidad" no es nuestro destino: es sólo un enemigo, aunque un enemigo peligroso.

La conclusión fundamental de nuestro análisis es que esta interacción puede ser positiva o negativa para el hombre, para su capacidad de supervivencia (recordemos el caso del ozono) o para su capacidad de realización (recordemos los nuevos tipos de disfunciones psicológicas que brotan en la sociedad tecnológica); por lo tanto, cualquier análisis crítico, cualquier propuesta seria en torno a la tecnología, sus límites y su campo de acción, ha de partir de la convicción de la prioridad del hombre y de la sociedad sobre el avance tecnológico. Aquí, en esta convicción, se encuentra el origen de las propuestas de una sociedad alternativa ${ }^{28}$, de unas tecnologías alternativas que no pongan en peligro las condiciones de supervivencia de la humanidad.

un punto de apoyo, analizando la tecnología y el hombre que ella configura, para enfrentarnos a la sociedad en que vivimos, intentando clarificar, desmitificar y reconducir lo que buenamente podamos hacia la superación de las carencias del hombre de finales del siglo XX.

27. RoBINETT, J., Etica y ordenadores; por dentro y fuera, en Anthropos, Revista de documentación científica de la cultura, $\mathrm{n}^{\circ}$ 94-95, Barcelona 1989, p. 114.

28. Cfr. SCHUMACHER, E.F., Lo pequeño es hermoso: por una sociedad y una técnica a la medida del hombre, Madrid, Herman Blume 1978. El autor propone desarrollar un nuevo estilo 
Al mismo tiempo, debemos enjuiciar nuestra sociedad consumista: la sociedad sólo es válida en la medida en que respeta al individuo, en la medida en que le ofrece un lugar para ser persona, para crecer en intercomunicación, realización productiva y cultural. En esta relación hombre-sociedad tecnológica, en la cual se ha de desarrollar el ser humano ("desarrollo" difícil de definir, pero que por la vía negativa ofrece unas condiciones indispensables de realización: descontaminación, comunicación, salud mental, bienestar material, elevación del nivel cultural y educativo, etc.), descubrimos el factor $n^{\circ}$ uno: el "poder" (tanto el tecnológico como el ideológico, el político o el de la información), factor que a menudo suele configurar el "desarrollo" en su propio beneficio. La situación de la Ciencia y la Técnica en el entramado de la realidad social concreta es un punto de arranque para desenmascarar ese "poder" y las imposiciones que pretende efectuar sobre nosotros, así como nos ofrece un punto de referencia: la no-realización del hombre y los mínimos exigibles para reorientar la sociedad de consumo y de alta tecnología de los años $90 .$.

\section{-La cuestión del fin: volviendo a Aristóteles}

$\mathrm{Al}$ comenzar este estudio, una cita de Aristóteles nos devolvía a la complejidad que ha de tener cualquier análisis que nos enfrente con la realidad. El problema central de la acción del hombre es la finalidad; hay que preguntarse por la finalidad de los proyectos tecnológicos, por la que se mueven y hacia la que se mueven. Respecto a esta cuestión, es interesante señalar la reflexión sobre la supuesta civilización del ocio que nos construye la moderna tecnología: según F. G. Jünger, la Técnica no incrementa el ocio, sino todo lo contrario: aumenta la masa cuantitativa de trabajo realizado mecánicamente, y la labor manual economizada por las máquinas no desaparece, sino que se desplaza dentro de la organización tecnológica. Al mismo tiempo, la masa de labor manual que se ha hecho dependiente de la mecánica también se incrementa. Además, Jünger afirma que la Técnica no crea riqueza: la organización Técnica sólo resuelve problemas técnicos. La Técnica sólo conoce, en realidad, coyunturas de explotación. La racionalidad de los procesos de trabajo técnicos es sólo aparente, pues esa racionalidad está puesta al servicio de la explotación exhaustiva y de la destrucción de la substancia (tanto de la tierra como del propio hombre). Mayor crítica no se le podía hacer al prurito tecnológico y su supuesta finalidad humanizadora.... ${ }^{29}$.

de vida, con nuevos métodos de producción y nuevas pautas de consumo, un estilo de vida disenado para la permanencia.

29. Junger, F.G., Perfección y fracaso de la técnica, Buenos Aires, Ed. Sur 1968. 
La reflexión sobre la tecnología nos debe llevar a los fines que la dirigen... ¿qué campo de realización nos ofrecen? Al preguntar por el fin, nos planteamos los límites de la sociedad tecnológica, los límites de los intereses económicos, bélicos o de poder que suelen guiar los proyectos tecnológicos, y nos decantamos por una tecnología alternativa y una sociedad alternativa que se orienten por otros factores (en primer lugar por el de la realización del individuo, vendido en una sociedad impersonal y consumista), y que construye un mundo distinto. La pregunta por el fin nos lleva, de nuevo, a Aristóteles, y de su mano a la filosofía: la reflexión planteada por la cuestión de la finalidad del movimiento socio-tecnológico actual nos conduce a la segunda parte de nuestro análisis: la reflexión sistemática efectuada por los filósofos y tecnólogos sobre la Ciencia y la Técnica contemporánea, y sus propuestas alternativas.

\section{REFLEXIÓN HISTÓRICO-SISTEMÁTICA SOBRE LA TÉCNICA}

La reflexión sobre la tecnología realizada por filósofos, ingenieros y tecnólogos puede agruparse en dos grandes corrientes, que se diferencian por sus opuestas valoraciones de la misma: aquellos que afirman la bondad del desarrollo tecnológico y lo fundamentan teóricamente (realizando un análisis de la tecnología en sí misma: la lógica propia de las formulaciones tecnológicas, sus conceptos y estructuras cognoscitivas, sus métodos y realizaciones concretas), y aquellos que critican tal desarrollo en base a los riesgos y peligros que ocasiona, confrontándolos con las características de la vida humana, a fin de analizar las desviaciones del objetivo humano en pos de otros objetivos (ya sean propios del sistema tecnológico, económico o político). Esta distinción nos acerca a la efectuada por D. Ihde entre una visión idealista (la que identifica progreso y Técnica) y una visión materialista (donde se sitúa la Técnica en un horizonte más amplio, en el que confluyen posturas filosóficas como el existencialismo, la fenomenología y la filosofía dialéctica) ${ }^{30}$.

Analicemos, pues, ambas corrientes:

\section{La reflexión de los ingenieros sobre la tecnología ${ }^{31}$}

Esta reflexión se caracteriza por la extensión del modo tecnológico de comprender la realidad a diversas áreas de conocimiento, y por la caracteri-

30. D. IHDE, Technics and Praxis, Boston, D. Reidel 1979, p. XVI.

31. Adoptamos la división propuesta por C. Mitcham en su obra "¿Qué es la filosofía de la tecnología?" y seguimos el hilo general de su argumentación, ya que dicha obra es el mejor estudio realizado hasta la fecha sobre la reflexión que han realizado los ingenieros en relación a la técnica. 
zación intrínseca de los procesos tecnológicos, en general acríticamente aceptados e identificados con la encarnación del progreso. En esta línea, Timothy Walker, en su obra "Defense of Mechanical Philosophy", afirma que la tecnología es un medio para hacer democráticamente disponible el género de libertad disfrutado por unos cuantos en una sociedad basada en la esclavitud. Pasemos a exponer los autores más relevantes de esta corriente:

\section{-Ernst Kapp}

Kapp fue el primer autor que utilizó la expresión "filosofía de la Técnica" (Philosophie der Technik). Hegeliano de izquierdas, trató de vincular la historia con la geografía de Ritter: "Para Kapp, la historia no era el despliegue necesario de la idea absoluta, sino el registro de los intentos humanos por enfrentar los desafíos de diferentes ambientes, por superar la dependencia de la naturaleza (...). Pero esto es sólo posible cuando la colonización externa del ambiente natural es complementada por una colonización interna del también humano" 32. Tras la Guerra de Secesión Americana, "emprendió la tarea de formular una filosofía de la tecnología, en la cual los instrumentos y las armas eran entendidos como diferentes tipos de proyecciones de órganos" ${ }^{33}$. Kapp elaboró esta idea detallada y sistemáticamente: "(...) la relación intrínseca que se establece entre los instrumentos y los órganos, relación que debe ser descubierta y enfatizada - si bien la misma es más un descubrimiento inconsciente que una invención consciente-, es que en los instrumentos lo humano se reproduce continuamente a sí mismo. Como el factor de control es el órgano cuya utilidad y poder deben ser aumentados, la forma apropiada de un instrumento sólo puede ser derivada de ese órgano. La riqueza de las creaciones espirituales brota, pues, de la mano, el brazo y los dientes. Un dedo doblado se convierte en un gancho, el hueco de la mano en un plato (...)" 34 . Pero no sólo eso: su libro "incluye - capítulo 10 la primera reflexión filosófica sobre la nueva Ciencia de la ingeniería mecánica (...) en la que encuentra similitudes entre la descripción de Ruleaux de la máquina como algo dotado de limitaciones metodológicas y el carácter de la ética que también propugna poner límites de principio a la acción humana. Finalmente, el lenguaje y el estado también son analizados como extensiones de la vida humana y de la res publica o externa de la naturaleza humana" ${ }^{35}$.

32. Mitcham, C., ¿Qué es la filosofía de la tecnología?, Barcelona, Anthropos 1989, p. 26.

33. Idem, o.c., p. 29

34. Citado por Mitcham, o.c., p. 30. Corresponde a E. KAPP, Grundlinien einer Philosophie der Technik, 1897, c. 3, pp. 44-45.

35. Idem, o.c., pp. 31-32. 
Aunque esta última reflexión supere de algún modo el marco estricto de la filosofía de la tecnología, al insertar ésta en una filosofía medio-ambiental sofisticada, lo más característico del análisis de Kapp es la ausencia de toda discusión dialéctica y la proyección que realiza de la perspectiva tecnológica de ver el mundo a una serie de ámbitos tradicionalmente no tecnológicos. Para Kapp, la tecnología se erige en punto de partida a la hora de analizar la realidad ${ }^{36}$.

\section{-P.K. Engelmeier y la tecnocracia}

"El intento de extrapolar el desarrollo y la efectividad de los procesos técnicos a otros ámbitos de la sociedad, ya sea a la organización política, social o económica, ha sido una de las constantes de los primeros pensadores que tomaron a la tecnología como objetos de reflexión. Este movimiento fue conocido con el nombre de tecnocracia y su influencia es claramente visible en todos los gobiernos actuales" ${ }^{37}$. Una vez caracterizada la "tecnocracia" en estos términos, como fenómeno de proyección de la Técnica, pasemos a describir brevemente la figura del ingeniero ruso P. K. Engelmeier, uno de sus primeros y principales defensores: Engelmeir constata el imperio de la tecnología, y al analizarlo descubre su esencia en el afán humano y en la voluntad interna de ese afán hacia la tecnología como medio de transformación de la realidad. La amplitud de la influencia de la tecnología nos obliga a un enfoque general de la cuestión: "Tenemos que investigar lo que representa la tecnología, los principales objetivos que persiguen sus distintas ramas, qué tipos de métodos usa, dónde termina su ámbito de aplicaciones, qué áreas de la actividad humana le rodean, su relación con la Ciencia, el arte, la ética, etc. Debemos desarrollar un cuadro completo de la tecnología, en el cual analicemos tantas manifestaciones Técnicas como sea posible (...), porque la tecnología es la primavera en el gran reloj mundial del desarrollo humano" ${ }^{38}$. Su proselitismo en favor de la racionalidad ingenieril le llevó a ser ejecutado por "contrarrevolucionario" a comienzos de los años treinta...

Junto a este intento de extrapolación de la lógica tecnológica a otras áreas de conocimiento, los primeros teóricos de la tecnología analizaron un tema de gran importancia: la "invención". El ingeniero M. Eyth considera la "invención" como el factor esencial que caracteriza la acción tecnológica:

36. KAPP, E., o.c., pp. 59-61.

37. MÉnDEZ, R., La filosofía de la tecnología en el siglo $X X$, en "Anthropos", Revista de documentación cultural, n 94-95, Barcelona 1989, p. 28.

38. Engelmeier, P.K., Allgemeine Fragen der Technik, en "Dinglers Polytechnisches Journal" 311, n² 14 enero 1899, p. 21. Citado por MiтCHAM, o.c., p. 33. 
ésta consiste en la "producción creadora de nuevas formas materiales" 39. Autores posteriores como Rodenacker acentuaron la importancia de la actividad creadora, del proceso de invención de la tecnología: Rodenacker "exige la formación de una propia 'teoría de la creación' de la Técnica en lugar de una teoría de la Ciencia de la tecnología" ${ }^{40}$.

Hasta ahora, el análisis de la estructura de la acción tecnológica nos ha llevado a autores que, tras caracterizarla, se detienen en dos elementos esenciales: la capacidad correctora y creadora de la tecnología en otros ámbitos, como solución a su secular desorden, y el estudio de la "invención" como característica propia del hacer tecnológico, invención o creatividad que se considera de la misma naturaleza que la artística o poética: "los ingenieros Max Eyth (1836-1906) y Alard Dubois-Reymond (nacido en 1860) (...) emprendieron, independientemente, el análisis del proceso técnico de invención (...). Es significativo que en todo esfuerzo similar posterior, invariablemente, el argumento en torno a la unicidad de la creatividad ha sido mantenido tanto en el dominio tecnológico como en el estético" ${ }^{41}$.

\section{-Friedrich Dessauer y la defensa de la creatividad tecnológica}

Dessauer ha sido el filósofo de la tecnología más destacado antes y después de la Segunda Guerra Mundial. En su reflexión sobre la tecnología intentó abrir un debate con los existencialistas, teólogos y teóricos sociales. Luchó por ser lo más ecuménico posible. Para él, lo fundamental en el análisis del conocimiento tecnológico aplicado por medio de la moderna tecnología consiste en el reconocimiento de lo tecnológico como un nuevo modo de existir en el mundo. De ahí su importancia y la necesidad de enjuiciar su poder, sus condiciones de ejercicio y sus consecuencias, así como las posturas éticas a tomar frente a él: "Dessauer intenta dar una explicación kantiana de las precondiciones transcendentales de este poder, así como reflexionar sobre las implicaciones éticas de su aplicación. Dessauer propone agregar una cuarta a las tres críticas kantianas — del conocimiento científico, de la actividad moral y del sentimiento estético-; se trata de una crítica de la actividad tecnológica" 42.

¿Cuál es la característica central de la actividad tecnológica? Para Dessauer, la actividad tecnológica es la experiencia pura de interacción con lo real, ya que en ella se supera la distancia (infranqueable, según Kant) entre fenómeno y número: "Dessauer argumenta que el hacer, particularmente en

\footnotetext{
39. MÉndez, R., o.c., p. 28.

40. Idem, o.c., p. 28.

41. MrTCHAM, C., o.c., p. 35.

42. Idem, o.c., p. 46.
} 
la forma de invención, establece contacto preciso con las cosas-en-sí" ${ }^{43}$. Por eso identifica la creación Técnica con la esencia de la tecnología. Al analizar las leyes de dicha creación, encuentra que se efectúa de acuerdo con las leyes que se utilizan a partir de los propósitos humanos. Ahora bien, el propósito es una condición necesaria pero no suficiente. Dessauer describe la esencia de la creación Técnica con el término 'elaboración' 44: esta 'elaboración' nos pone en contacto con la realidad trascendente, en sí, de los objetos técnicos, ya que la invención no es un sueño ni una imaginación, sino un encuentro de nuestro conocimiento con el reino de los problemas técnicos y sus soluciones preestablecidas; comprende "la existencia real originada en las ideas", el material imbuido de una realidad trascendente ${ }^{45}$. Sitúa la superación de la experiencia en el ámbito de la experiencia tecnológica. Dado que la tecnología nos relaciona con la realidad en sí, la búsqueda de ésta es un imperativo ético: "En Dessauer la tecnología se convierte en una experiencia religiosa, y la experiencia religiosa toma un significado tecnológico" ${ }^{46}$.

Para Dessauer, mediante la creación Técnica el hombre participa de la creación divina.

- La perspectiva analítica y la reflexión de los ingenieros alemanes actuales: Simon Moser, Hans Lenk, Alois Huning, Günter Rophol, Hans Sachsse, Friedrich Rapp

La perspectiva analítica a la hora de estudiar la tecnología ha sido reforzada por la filosofía de la Ciencia, que ha relegado los estudios específicos sobre la Técnica en base a la distinción tajante entre Ciencia y Técnica ${ }^{47}, \mathrm{y}$ entre cuestiones epistemológicas y cuestiones sociales. Los filósofos de la Ciencia (tipo Russel o Carnap) han insistido principalmente en el estudio de las cuestiones metodológicas de la Ciencia y en la caracterización formal del lenguaje científico. Debido a esta perspectiva teoricista y logicista, identifican la Ciencia con las teorías científicas, con lo que ofrecen una comprensión instrumental de la Ciencia, basada en un conocimiento teórico "neutral" (supuesto que criticamos en la primera parte de nuestro estudio): 'La Ciencia y sus aplicaciones tecnológicas son buenas en sí mismas, sólo es malo el uso que de ellas realizan los políticos y usuarios'. Autores como Mario

43. Idem, o.c., p. 47.

44. El término alemán utilizado por Dessauer es "inner Bearbeitung". Cfr. Philosophie der Technik: das Problem der Realisierung, Bonn, F. Cohen 1927, pp. 160-180.

45. Dessauer, F., Discusión sobre la técnica, 1964, p. 244.

46. Mitcham, C., o.c., p. 48.

47. Para un análisis de los orígenes del mito teoricista de la ciencia, cfr. MEDINA, M., De la techne a la tecnología, Valencia, Tirant lo Blanch 1985. 
Bunge defienden esta concepción: "la Ciencia es inocente, pero la Técnica puede ser culpable" 48 .

El desarrollo en Alemania de una filosofía de la Técnica, en colaboración con las universidades politécnicas y con el VDI, estuvo muy influido en sus primeros pasos por los métodos propios de la filosofía analítica: "su análisis se ha centrado fundamentalmente en la naturaleza propia de la tecnología", y, aunque no dividen estrictamente entre Ciencia y Técnica, "el objetivo de dicho estudio sistemático de filosofía de la tecnología es encontrar una concepción teórica general (...) . En definitiva, se trata de desarrollar un Ciencia de la Técnica" ${ }^{49}$. El mejor exponente de este intento es la obra de F. Rapp sobre filosofía de la Técnica ${ }^{50}$. Ahora bien, es necesario señalar que el desarrollo analítico de la tecnología produce un movimiento legitimador de las realizaciones tecnológicas, basado en el supuesto teoricista que afirma la neutralidad de la Ciencia y la tendencia hacia la verdad y el bien del proceso de creación tecnológico. Volvemos a repetir que este supuesto es fácilmente cuestionable y difícilmente defendible... ${ }^{51}$.

\section{La reflexión de los filósofos sobre la tecnología:}

\section{- Lewis Mumford: el mito de la máquina.}

Como enfoque general de la crítica realizada a la tecnología Por Lewis Mumford, valga la contextualización que de su obra hace C. Mitcham: Lewis Mumford "basó su vida en las humanidades, y ha sido un crítico persistente de la tecnología en la tradición norteamericana del romanticismo terrena, que se extiende desde Ralph Waldo Emerson hasta John Dewey. La tradición es terrenal por su preocupación por la ecología del medio ambiente, la armonía de la vida urbana, la preservación de la tierra virgen y una sensibilidad hacia las realidades orgánicas. Es romántica al insistir en que la natura-

48. Título de la conferencia impartida por Mario Bunge en el Congreso Interamericano de la Filosofía de la Tecnología, Recinto universitario de Mayagüez, Universidad de Puerto Rico, octubre de 1988.

49. MÉNDEZ, R., o.c., p. 29.

50. RAPP, F., Filosofía analítica de la técnica, Barcelona, Laia 1981.

51. El desarrollo de la ciencia es relativamente autónomo, y con una relatividad bastante precaria... Así, M. Shallis, en su obra "El ídolo de Sicilio", analiza la historia de informática y concluye su reflexión con una crítica de la visión neutralista de la ciencia y con un ataque a la identificación del progreso tecnológico con el progreso en sí: el futuro de la ciencia y la tecnología depende más de los poderes político y económico que del desarrollo autónomo de aquéllos. Sus investigaciones, presentes y futuras, están marcadas tanto por los intereses que han motivado su desarrollo original como por los presentes. Shallis observa que el desarrollo de la informática está ligado estrechamente a la investigación con fines militares... En obras como la de Shallis es bien patente que la "ingenuidad" está cada día menos de moda entre los teenólogos y los analistas del progreso tecnológico. Cfr. SHALlis, M., El ídolo de sicilio, Barcelona, Salvat 1986. 
leza material no es la explicación final de la actividad orgánica, al menos en su forma humana. Las bases de la acción humana son la mente y la aspiración humana por una autorrealización creativa" 52.

Mumford parte de una concepción antropológica determinada a la hora de analizar el desarrollo tecnológico, concepción que va tomando cuerpo en el curso del mismo. Para Mumford, el 'saber', en cuanto pensamiento, priva sobre el 'hacer', con lo que la mente se convierte en el factor básico de la humanidad, y constituye su esencia en cuanto 'creatividad': la esencia humana es la invención y la interpretación. Por lo tanto, la tecnología, en cuanto fabricación de máquinas, no es el agente principal de la historia, sino que obedece a la satisfacción del mundo supraorgánico que constituye la esencia del hombre; los productos tecnológicos son "más para utilizar sus propios ingentes recursos económicos con miras a satisfacer más adecuadamente sus demandas y aspiraciones supraorgánicas, que para el propósito de incrementar el abastecimiento de alimentos o controlar la naturaleza" 53. "El hombre es preeminentemente un animal pensante, autodominado y autodiseñado" ${ }^{54}$.

Sobre esta antropología, Mumford distingue dos tipos de tecnologías, autoritaria y democrática, según la relación que la tecnología mantenga con las formas específicas de el poder existentes ${ }^{55}$ : la politécnica, forma primordial de acción, estuvo "ampliamente orientada hacia la vida, no centrada en el trabajo o en el poder" 56, y la monoTécnica, que se "basa en la inteligencia científica y la producción cuantificada, se dirige principalmente hacia la expansión económica, plenitud material y superioridad militar" 57 . La primera se orienta a satisfacer las diferentes necesidades de la vida y funciona democráticamente, porque sus objetivos son plurales y humanos. La segunda da origen a la 'megamáquina', rígida organización social jerárquica que produce grandes beneficios materiales, pero a costa de una deshumanización del individuo, que ve limitadas sus actividades y aspiraciones específicamente

52. MiTCHAM, C., o.c., p. 53.

53. MUMford, L., El mito de la máquina, vol. 1, Buenos Aires 1969, p. 8.

54. Idem, o.c., p. 9.

55. Las obras de Mumford tratan de averiguar cuál es la mejor forma de satisfacer las necesidades humanas, buscando alternativas sociales o tecnológicas a la sociedad presente. El estudio de las repercusiones éticas, políticas, ecológicas, sociales y metafísicas de la técnica contemporánea debe conducir a un replanteamiento activo de las carencias y defectos de la sociedad actual. La reflexión histórica nos permite liberarnos del falso mito de la "necesidad" de las encarnaciones prácticas de la técnica que configuran el mundo actual: podemos intentar reorientar el proceso, y, de hecho, la gran cantidad de publicaciones sobre este tema son producto de la insatisfacción y la necesidad de reorientación de una sociedad tecnológica con fuertes lacras...

56. Idem, o.c., p. 9.

57. Idem, El mito de la máquina, vol. 2, 1970, p. 155. 
humanas. Mumford critica la actual civilización pluralista y una "economía bioTécnica" ${ }^{58}$. Su intención última es buscar una tecnología que esté de acuerdo con la naturaleza humana y supere sus actuales desequilibrios. El hombre se hizo hombre abandonando el reino animal, "no porque hiciera del fuego su sirviente, sino porque hizo posible, por medio de sus símbolos, expresar confraternidad y amor, enriquecer su vida presente con recuerdos vívidos del pasado e impulsos formativos hacia el futuro, ampliar e intensificar aquellos momentos de la vida que tuvieron valor y significación para él" 59. La tecnología no debe servir al poder, sino al hombre; y al hombre democrático y plural, no al dogmático y autoritario. Como podemos observar, Mumford establece un patrón desde el que juzgar las realizaciones concretas de la Técnica: el hombre, concebido con una estructura antropológica concreta. La finalidad de la Técnica es la potenciación de la vida de ese hom- . bre antropológicamente sano: plenificación de una naturaleza que tiende a realizarse, concepción que nos devuelve al concepto griego de la naturaleza humana y de la vida como algo que tiende a alcanzar una configuración en plenitud.

\section{- José Ortega y Gasset}

Al igual que Mumford, Ortega basa su análisis de la tecnología en una concepción antropológica muy determinada, y con un carácter más metafísico: la vida humana supone una relación con las circunstancias ("yo soy yo y mi circunstancia" ${ }^{60}$, como activa creadora de las mismas. Al criticar a Husserl, Ortega desarrolló su filosofía a partir de una intencionalidad existencial consistente en la coexistencia del ego con las circunstancias, una coexistencia creadora y activa que conforma a las mismas. El hombre se autocrea y autointerpreta, y esta recreación de su existencia se efectúa en dos planos distintos: en primer lugar, existe una actitud hacia el mundo, un proyecto que la persona quiere realizar; en segundo lugar, está la realización concreta de tal proyecto, realización material que requiere conocimientos técnicos. Aquí radica la importancia de la Técnica para el hombre: la Técnica es esencial al ser humano, existiendo tantas Técnicas como proyectos. Por la Técnica el hombre concreta en el mundo real su intencionalidad creativa.

Ortega estructura la creatividad humana en dos fases; en un primer momento el hombre inventa en su interior algo que desea, y que surge en

58. Idem, The Culture of Cities, New York, Harcout Brace 1938, p. 409.

59. Mumford, L., Art and Technics, New York, Columbia University Press 1952, p. 35.

60. El sentido de la conocida frase de Ortega es el siguiente: "La vida como aceptación de la circunstancia implica que el hombre no puede salvarse si, a la vez, no salva su contorno", Obras Completas, vol. VIII, p. 56. 
contraposición a la naturaleza, de la que se desmarca construyéndose a sí mismo (el origen de la Técnica está en la capacidad de 'desear', trascendiendo los límites de lo dado por la naturaleza) ${ }^{61}$. Tras formular su deseo, en un segundo momento el hombre realiza esa invención en la práctica, en una proyección que crea sus propios medios artificiales, humanos, y que, por lo tanto, no es estrictamente orgánica. Esos medios que permiten la realización del hombre, que permiten su expresión material, son los medios técnicos. Por eso el ser humano es un ser 'técnico' ${ }^{62}$. La Técnica surge por el afán humano de crear un nuevo mundo, el mundo del hombre, distinto de lo dado por la naturaleza ${ }^{63}$. Los actos técnicos se caracterizan por constituir una reforma de la naturaleza, en cuanto anula dichas necesidades naturales. A través de la Técnica el hombre no se adapta al medio, sino que adapta el medio a su persona, construyendo una supra-naturaleza, con la que se identifica más plenamente. El hombre resulta ser a un tiempo natural y extranatural, ya que no se limita a satisfacer sus necesidades básicas de supervivencia, sino que, para él, lo extra-natural, lo superfluo (en cuanto creado a partir de su intencionalidad) se convierte en lo necesario para vivir, de tal forma que identifica su verdadera vida con ese vivir lo superfluo (entendiendo por superfluo la creación propiamente humana), con el "bienvivir".

En su análisis histórico, Ortega distingue tres períodos fundamentales: la Técnica del azar, la Técnica del artesano y la Técnica del técnico o del ingeniero. Se diferencian por la diferente fabricación de los medios para realizar el proyecto que diseñan los humanos, y en el que quiere convertirse, dejando de ser mera naturaleza. Pero sólo en el tercer período, en la actualidad, cuando aparece la Técnica moderna, (que se caracteriza por definir las condiciones y los medios de realización de un proyecto antes de elegir un proyecto concreto), se puede hablar de tecnología como un saber distinto de los

61. Idem, Obras Completas, Madrid, Revista de Occidente, vol. IX, p. 618.

62. "Lo que nadie puede dudar es que desde hace mucho tiempo la técnica se ha insertado entre las condiciones ineludibles de la vida humana de suerte tal que el hombre actual no podría, aunque quisiera, vivir sin ella", Idem, Meditación de la técnica, o.c., p. 14.

63. Esta oposición hombre-Naturaleza, relación de la que se escapa el hombre para crear a su vez un mundo específicamente humano, técnico, mundo que, dialécticamente, se vuelve contra él erigiéndose en dominador, nos remite a la famosa descripción hegeliana de la relación amo-esclavo, en la Fenomenología del Espíritu, en la cual se rompe el ideal cartesiano del sujeto como controlador y creador de un mundo mecánico que está a su servicio y que es puramente pasivo. En la realidad tecnológica del siglo XX, los papeles no están tan claros. Fromm también desarrolla su análisis de la naturaleza humana a partir de esta confrontación con la Naturaleza, en la que el hombre crea un mundo con autonomía suficiente como para dominar a su creador. Por último, conviene resaltar la presencia del análisis marxista de la fetichización de la mercancía, reificación de una creación humana que oscurece su origen y se vuelve dominadora del hombre concreto (cfr. MARX, K., El Capital, Madrid, siglo XXI 1975, pp. 88-89). Como vemos, este tema tiene una larga tradición histórico-filosófica. 
proyectos concretos. Esta perfección de la Técnica engendra un peligro, y es el de la desaparición de la facultad imaginativa o de desear, motor originario de la Técnica (que surge por el deseo del hombre de dejar de ser naturaleza). Ante la posibilidad de lograr cualquier fin, se pierde la capacidad de elegir fines, con lo que caemos en la dinámica de las estructuras económicas, de poder, ideológicas o de clase. La Técnica contemporánea "es incapaz de determinar el contenido de la vida" ${ }^{64}$, a diferencia de las Técnicas de otras épocas, ligadas esencialmente a los proyectos del hombre concreto.

En Ortega encontramos, al igual que en Mumford, la búsqueda de un fundamento para enjuiciar el progreso tecnológico. El fundamento consiste en un concepto determinado de la esencia del hombre, de su realidad más específica, concepto que ambos autores contrastan con las consecuencias del avance tecnológico de nuestros días: ambos no sitúan la lógica propia de la formulación tecnológica como un fin en sí mismo, ni el progreso tecnológico como finalidad de la historia, sino que lo contrastan con la realización del hombre concreto, realización que trasciende las posibilidades de la tecnología y que debe orientarla.

\section{- Martin Heidegger}

Heidegger aborda el problema de la Técnica desde un punto de vista ontológico, relegando a un segundo plano el enfoque antropológico de Ortega o Mumford. Concibe la Técnica como un tipo de verdad, en el sentido de un des-ocultar o des-velamiento. Heidegger comienza su estudio sobre la Técnica analizando las similitudes y diferencias entre la Técnica antigua y la moderna: ambas son medios para ciertos fines. Heidegger concluye que ambas pertenecen al reino de lo instrumental, en el que impera la causalidad (en el que persiguen fines empleando medios). Ahora bien, la pregunta por la causa lleva a la pregunta por el des-ocultar, ya que en el des-ocultar se funda todo producir. Heidegger, que concibe la verdad en términos de $\alpha \lambda \eta$ $\theta \varepsilon \imath \alpha$, afirma que a partir del des-ocultar se abre un ámbito diferente, el de la verdad, ya que la verdad aparta el velo que tapa la realidad y nos deja a solas con la realidad misma: "La Técnica es un modo de desocultar. La Técnica despliega-su-esencia en el ámbito donde acontece el desocultar y el estadode-no-oculto, donde acontece la aletheia, la verdad" 65 .

Heidegger se plantea el problema de la Técnica desde tres perspectivas ${ }^{66}$ :

1. En primer lugar, vincula la pregunta por la Técnica a la pregunta por la cosa: para Heidegger, la tecnología moderna genera un mundo específico,

64. Idem, o.c., p., 81 .

65. Cfr. Heidegger, M., La pregunta por la técnica, en "Ciencia y Técnica", Santiago de Chile, Ed. Universitaria 1984, pp. 88 y ss.

66. Cfr. Miтcham, C., o.c., pp. 64-72. 
Bestand, (lo constante), un mundo compuesto por cosas que no son 'cosas' un sentido genuino: "Bestand consiste en objetos sin valor inherente, a parte del uso que le pueda dar el ser humano" ${ }^{67}$. La objetivización que del mundo realiza la tecnología científica, al representarlo en términos matemáticos, ignora su carácter terrenal y ofrece la posibilidad de "producir objetos sin real individualidad o cosificidad" 68 .

2. En segundo lugar, Heidegger se plantea la pregunta por la Técnica en relación a la desvelación que ésta produce del mundo como objeto puro. ¿En qué se basa esta desvelación? Para Heidegger, lo que yace detrás de la tecnología moderna es lo "dispuesto" o "Gestell", la actitud tecnológica hacia el mundo, la precondición trascendental de la tecnología moderna. Este 'dispuesto' "significa lo reunidor de aquel poner que pone al hombre, lo provoca a desocultar lo real en el modo del establecer en cuanto lo constante" 69 . Esta disposición no es individual, sino impersonal, una voluntad impersonal que 'pone' y 'provoca' al mundo y 'pone' y 'provoca' a los seres humanos a 'poner' y 'provocar' el mundo. "Heidegger quiere decir, tal vez, que el mismo hecho de que la realidad se mantenga abierta a la manipulación tecnológica, en cierto modo, pone en acción tal manipulación" 70.

3. En tercer lugar, Heidegger reflexiona sobre la relación social entre Técnica y ser: "la tecnología moderna no sólo encubre y oscurece la cosificidad en las cosas, sino que también encubre y oscurece al ser en los seres y finalmente, a sí mismo. La tecnología no puede ser entendida con más tecnología" ${ }^{71}$. ¿Por qué? Porque la tecnología se caracteriza por una lógica férrea y dogmática, que trata acerca de cómo fabricar los objetos técnicos. Y esta lógica cerrada no puede conocer sus propias limitaciones en otros planos, argumentación que nos recuerda la crisis a la que conduce el solipsismo de la filosofía logicista del neopositivismo, centrada en la exclusividad de la formalización de un lenguaje científico perfecto. La tecnología no presta atención a la dimensión metaFísica del hombre, y olvida aspectos vitales de la vida humana. Para Heidegger, la forma de superar la tecnología es la pregunta por sus límites y por las dimensiones del propio preguntar tecnológico, contrastando este preguntar a otros tipos de experiencias, como la meditación, el arte o la poesía. La tecnología sólo se superará ẹn el "preguntar único", y este preguntar es "la devoción del pensar" 72.

67. Idem, o.c., p. 68.

68. Idem, o.c., pp. 68-69.

69. HeidegGer, M., o.c., p. 88.

70. Mitcham, C., o.c., p. 70.

71. Idem, op.c., p. 70-71.

72. Heidegger, M., o.c., p. 107. 
Heidegger nos ofrece un análisis de la tecnología en el cual ésta queda trascendida en el encuentro con el Ser, y esta necesidad ontológica es la qui nos ofrece una plataforma para criticar el actual mundo tecnológico, en cuanto cerrado a ese preguntar único. El conocimiento es la finalidad desdc la cual se cuestiona la realización Técnica (el conocimiento del Ser), ya que, para Heidegger, dicho conocimiento es el objeto de la experiencia humana de la vida. Por tanto, Heidegger nos plantea una dimensión externa a la Técnica, desde la cual enjuiciarla, una dimensión meta-Técnica, ontológica (en cuanto en la pregunta por el Ser se realiza el hombre). Nos ofrece una perspectiva para enjuiciar críticamente la Técnica y nuestra vida actual.

\section{CONCLUSIÓN}

La conclusión de este estudio, que pretende caracterizar brevemente el impacto de las nuevas tecnologías en la sociedad contemporánea y la reflexión efectuada sobre las mismas por filósofos y tecnólogos, no puede consistir sino en el planteamiento de una serie de cuestiones abiertas, que nos retan a una investigación más detenida con un fin, a mi modo de ver, primordial: la definición de las necesidades del hombre, la descripción de sus carencias actuales, y la exposición de los límites y potencialidades de los productos tecnológicos. El objetivo es lograr una mejor simbiosis entre necesidad humana y creación tecnológica.

Es el desfase entre estos dos elementos el que produce situaciones como las actuales, en las que se destruye el medio ambiente para conseguir beneficios económicos a corto plazo (dificultando las condiciones de supervivencia del hombre en un grado progresivo que aún está sin evaluar), y en la que se olvida la dimensión humana del individuo, sumergiéndolo en una dinámica de poder, consumo y competitividad que no está orientada hacia la realización del ser humano, sino hacia la perpetuación del sistema. Volvemos al cuadro descrito por $\mathrm{Hegel}$, en su exposición de las relaciones entre el amo y el esclavo... ¿quién es el amo, quién es el esclavo, hoy día?

Un estudio esclarecedor sobre este punto podría ser el análisis de las 'nuevas necesidades' en el consumidor por medio de las campañas de marketing y publicidad. ¿A quién beneficia esa 'creación' de nuevos productos, esa creación de estímulos que sólo se satisfacen con una respuesta de consumo? ¿A quién beneficia el acceso a la dignidad y la identificación social por medio de objetos de usar y tirar, perecederos, y sin existencia en un sentido ontológico profundo, ya que su sentido es ser sustituido por otro, sin motivo en sí mismo, sino como medio de mantenimiento del sistema? Creo que es 
importante realizar un análisis profundo sobre los 'objetos' que inundan nuestra vida cotidiana, y sobre la capacidad de los mismos para provocar un crecimiento del hombre....

Precisamente, la objetivización de los criterios de satisfacción e identificación conduce a una dinámica de 'posesión' de la realidad, a una dinámica de 'reconocimiento' e 'identificación' en una serie de objetos que se sustituyen rápidamente y que nos encadenan a una repetición compulsiva del adquirir y desechar. ¿Qué tipo de relación nos ofrecen los objetos, las "cosas" producidas por el sistema tecno-económico; a qué tipo de creatividad, de formulación de sentido ante la vida (propio, esforzado e imaginativo) nos remite y capacita la lógica de la sociedad tecnológica de consumo? La carencia de finalidad que señalaba Ortega se convierte en la omnipresencia de un fin efímero y caduco: el objeto de consumo (un consumo no gratificante, por cuanto existe y es producido por una sociedad que repite compulsivamente la adquisición de productos, y que refuerza diariamente esa 'pulsión' consumista a través de los mecanismos publicitarios).

Pero la pregunta por la tecnología no sólo nos enfrenta a la sociedad de consumo; también nos enfrenta a las sociedades de poder o ideológicas. Y, fundamentalmente, nos enfrenta a un nuevo punto de partida desde el que reflexionar críticamente sobre la realidad (una realidad configurada tecnológicamente en nuestros días). En relación a este proyecto crítico ${ }^{73}$, creo conveniente resaltar los siguientes puntos claves en toda reflexión sobre la tecnología actual:

\section{- La crítica del supuesto teoricista de la neutralidad de la Ciencia}

Nos hemos referido con frecuencia a este punto a lo largo de nuestro estudio. La concepción de la Ciencia como búsqueda de la verdad, búsqueda orientada solamente por intereses intelectuales, da origen a una visión que concibe la Ciencia como algo neutral, independiente de la comunidad en la que se aplica, y orientada fundamentalmente hacia el progreso ( $\mathrm{y}$ hacia el bien): "En el ámbito de la Ciencia moderna, la distinción filosófica entre Ciencia pura, característicamente teórica, y Ciencia aplicada, básicamente tecnológica, ha servido para legitimar la exigencia de total autonomía para la investigación científica, junto con la exención de los científicos de toda responsabilidad por las consecuencias negativas de sus investigaciones" ${ }^{74}$. Es, pues, la noción de verdad purá y teórica lo que justifica el desarrollo científi-

73. Recordemos el interés de Dessauer por elaborar una cuarta crítica, la crítica de la tecnología. Cfr. Dessauer, F., Discusión sobre la tẹcnica, Madrid, Rialp 1964.

74. Medina, M., Mito de la teoría y filosofía de la tecnologia, en "Anthropos", Revista de documentación cultural, $\mathrm{n}^{\circ}$ 94-95, Barcelona 1989, p. 35. 
co. Pero a lo largo del siglo XX hemos descubierto cómo la Ciencia no es algo independiente de la sociedad en la que se realiza, sino que depende de ésta y fija sus objetivos en base a la relación dialéctica que mantiene con la misma. Las finalidades de una determinada 'sociedad' o 'grupo de poder', que impregnan una comunidad científica dada, pueden ser el polo opuesto de lo que normalmente entendemos por 'verdad' o 'bien' (ejemplos concretos hay miles; recordemos el desarrollo de la tecnología militar en países caracterizados por el dominio absoluto de una clase o de una ideología, o pertenecientes al mundo subdesarrollado...). Al analizar las claves que guían el desarrollo científico y técnico, observamos cómo en la actualidad, tras la concienciación producida por las dos guerras mundiales y las contradicciones del desarrollo tecnológico, la justificación por medio de la noción de verdad (y la búsqueda de la misma), con su neutralismo implícito, ha sido sustituida por la justificación en términos de operatividad, eficacia y consumo, dándose como dato inamovible la necesidad de apuntalar el sistema de consumo consumiendo..., aunque tal actividad nos encadene a una alienación perpetua.

Desde esta nueva perspectiva del desarrollo de la Ciencia y de la Tecnología, podemos resituar sus logros en el contexto social en el que surgen, huyendo de toda mitificación, y contrastándolos con las condiciones de una búsqueda de una vida humana más justa y equitativa, más plena y realizada. Es este conocimiento de la dinámica interna que origina, justifica y financia la actividad tecnológica, el que nos aporta las armas suficientes para no ser 'ingenuos' y para poder ejercer una crítica seria y constructiva. Es la historia del hombre la que nos lleva, como único medio de supervivencia, a una visión crítica de la sociedad tecnológica contemporánea: "la tecnología no es neutral, puede usarse para satisfacer necesidades humanas o para crear otras superfluas, para la industria civil o para la industria militar, para el bien o para el mal. Su conceptualización, análisis, desarrollo y control es más que un mero juego académico (...)" 75 .

Estos datos nos llevan de nuevo a la reflexión filosófica, a la reflexión sobre la base antropológica que necesitamos para reorientar la tecnología ${ }^{76}$ y poder criticarla propositivamente. La pregunta por el hombre concreto y

75. TOBAR, J.F., Tecnología y economía, en "Anthropos", Revista de documentación científica de la Cultura, ${ }^{\circ}$ 94-95, Barcelona 1989, p. 94.

76. En la reflexión filosófica contemporánea no está de moda el "humanismo". Es difícil mantener que el hombre es el centro del universo, y, como ya indicamos al referirnos a Hegel, la creación técnica del hombre se ha independizado del mismo y hoy en día el hombre concreto está sometido a ella. Sin embargo, me resisto a admitir sin más que no es posible enfocar de una manera más "humana" la cuestión, sobre todo porque esta postura suele llevar a un apuntalamiento del sistema, consecuencia claramente reprobable. Si no es posible "reórientar" la civilización actual (ingenuo idealismo ilustrado, dirían algunos), sólo nos queda el papel de voceros 
por sus posibilidades de realización nos remite a los análisis de Ortega, Mumford, Heidegger, Ellul, y otra larga serie de autores que indagan en el mundo actual para poder caracterizarlo, para poder dibujar sus avances y defectos, y para poder superarlo (o trazar líneas de posible reordenación del mundo tecnológico de cara a la consecución de un mundo más humano). La Técnica y la sociedad basada en ella deben confrontarse con las necesidades básicas del hombre, no sólo biológicas, sino biológico-existenciales (recordemos la importancia de lo supra-orgánico en Munford y Ortega)... ¿Cómo acceder a esa caracterización? A mi modo de ver, un posible método sería el método de definición 'negativo', basado en la descripción de las carencias reales, reflejo de lo que el hombre quiere ser y no puede: a la luz de estas carencias podremos definir las necesidades del hombre y acercarnos a la forma mejor de satisfacerlas. En todo caso, es una tarea abierta a investigaciones posteriores.

- La evolución de las nociones claves de la Ciencia bajo el impacto de las nuevas tecnologías: definición del status epistemológico de la creación y los conceptos científico-técnicos

Este segundo tema de reflexión está íntimamente ligado con el anterior, ya que el análisis de la noción de consumo y su evolución, de la noción de eficacia y su evolución de las nociones de riesgo y control, y su evolución respectiva, nos sitúan ante una perspectiva totalmente distinta del status epistemológico de la Ciencia tecnológica y de sus realizaciones, y definen de distinta manera la 'verdad' de la Ciencia y de la tecnología, y su respuesta a una

nuestra sociedad del paro y del consumo, ya que, aunque no queramos, la negación de la posibilidad de pensar y luchar por una sociedad más humana refuerza el sistema de poder y tecnológico que rige nuestra vida diaria. En otras palabras, tomamos partido por la estructura tecno-económica, declarándonos partidarios de la negación de lo específicamente humano como objetivo de nuestra cultura y nuestra sociedad. Y sin embargo, frente a esta postura, la sociedad reclama una reorientación del avance tecnológico, que se hace a costa de poner en peligro la supervivencia de la especie humana (y, de paso, de todas las demás); los tecnólogos (ya lo hemos visto al analizar la corriente crítica de la VDI) se cuestionan los avances tecnológicos y buscan criterios de decisión. Hay una gran polémica en torno a la cuestión de los aspectos legales y éticos de las nuevas tecnologías, debido a los problemas planteados por la tecnología de la información y la biogenética. Desde todos los campos del progreso tecnológico y social se buscan criterios (no abstractos, a priori y evidentes como los cartesianos o kantianos - sin caer en el error de identificar unos con otros-, sino concretos, basados en la necesidad de evitar las consecuencias negativas de la tecnología, negatividad que se entiende referida al ecosistema y al hombre), búsqueda que siempre confluye en un concepto de hombre determinado y en la defensa de lo considerado básico para la vida humana. Frente al escepticismo de los desilusionados, la vida misma nos exige un esfuerzo de reflexión filosófica, una nueva búsqueda de criterios (plurales, limitados, distintos de los de otras épocas, pero criterios, perspectivas desde las que juzgar al fin y al cabo), un renovado intento de pensar la sociedad para poder evitar la fatalidad de lo dado como necesario, recuperando la iniciativa. Ésta es la tarea de nuestros días. 
búsqueda práctica, ligada a intereses socio-económico-culturales, que se constituye en su motivo fundamental de existir, (desgraciadamente, el afán de encontrar una verdad indubitable en la moderna Física y en la Ciencia en general ha entrado en crisis tras conocerse los estudios sobre la Historia de la Ciencia de Kuhn, Feyerabend, etc.).

Estas nociones nos remiten continuamente a un entramado social, caracterizado por sistemas económicos, políticos y tecnológicos que poseen una dinámica ajena al hombre concreto. Desde la caracterización de la Ciencia y la Tecnología a partir de dichos conceptos, podremos elaborar una postura ética y de control del crecimiento tecnológico (no control férreo, sin duda imposible, pero sí de autoconciencia y orientación a la luz de las dificultades y de las defiCiencias del desarrollo tecnológico), distinta y superior a la actual, que sigue siendo esclava de la mitificación teoricista de la Ciencia, de la convicción de la neutralidad de la misma y del bien intrínseco de toda producción tecnológica, ya que en la Ciencia operativa se encarna el progreso histórico. El análisis de estas nociones y de la Ciencia y la Técnica que se desarrollan sobre su base, así como el de la sociedad en la que crecen y a la que condicionan, es un objetivo abierto a futuras investigaciones en este campo.

\section{- Las cuestiones éticas y la necesidad de un fin}

La reflexión ética tiene mucho que decir ante la multitud de problemas generados por la aplicación de las nuevas tecnologías. Dado que toda ética remite a una metaFísica determinada, y a un cierto concepto del ser humano y de la sociedad, la reflexión filosófica adquiere visos de urgencia histórica en el mundo contemporáneo. Pero ha de ser una reflexión filosófica fundada en el elemento configurador de nuestra sociedad; la tecnología contemporánea, ya que desde ella surgen las grandes características de nuestro mundo tecnificado, su aplicación provoca los mayores problemás y désde ella se está configurando un nuevo modo de existir en el mundo: un nuevo modo de sercon-la-tecnología, un nuevo modo de ser-en-el-mundo. Pongamos un ejemplo: "Una forma de empezar a ver los problemas de los ordenadores y la ética es examinar el asunto más candente y que genera la mayor ansiedad; la pérdida de control sobre la información personal y la resultante pérdida de privacidad (...). La amenaza a la privacidad individual descansa tanto en la cantidad como en el tipo de información contenida en esos registros, así como la manera en que la información es registrada en los bancos de datos y la fácil accesibilidad a los sistemas computarizados por una gran cantidad de usuarios tanto autorizados como no autorizados" ${ }^{77}$. Si la toma de decisiones

77. RoBinetT, J., o.c., p. 115. 
efectuadas a través de los medios de alta tecnología no tiene en cuenta una dimensión ética, podemos esperar que se cometa cualquier tipo de barbaridad: "Un sistema de red neural, sin importar cuán poderoso sea, sólo puede trabajar con la información que haya recibido de los programadores y diseñadores. Si esta información no descansa en un fundamento ético, las decisiones tomadas no tendrán ningún punto de referencia ética. El problema de cómo añadir una enseñanza ética a estos sistemas se hace más urgente ya que estos sistemas son o serán capaces de tomar decisiones cruciales en nuestras vidas. (...) todos dependemos de los individuos (...) que usan los sistemas de ordenadores y los bancos de datos, y de su integridad personal. Sin un claro sentido de la ética, estas personas no tendrán pautas para manejar la información con el cuidado requerido (...) La enseñanza ética no debe ser descartada o ignorada en el desarrollo de las redes neurales. Tampoco deben faltar las bases éticas en los sistemas basados en reglas. La idea de Kant de que la gente no debe ser tratada como un medio sino como un fin en sí mismo, necesita ser reevaluada a la vista de la era de la información en que vivimos, para así incluir no sólo la vida Física de cada individuo sino también el complejo de la información personal y los sistemas de toma de decisiones que nos rodean y sostienen esa vida" ${ }^{78}$.

Necesitamos, pues, una ética que configure nuestra vida, que señale fines, porque sólo respecto a ellos podemos juzgar y reorientarla ${ }^{79}$, porque

78. Idem., o.c., p. 118.

79. Respecto a la cuestión de los fines, hemos de señalar que el fin último de la tecnología y de nuestra postura ante el mundo no puede ser el mero provecho, "aquí y ahora", del hombre: matar halcones porque cazan palomas y nosotros queremos cazar palomas es un despropósito. La destrucción del ecosistema en nuestro propio beneficio acaba siendo nuestro mayor perjuicio. Al hablar del hombre y de un nuevo humanismo, no participamos de la teoría del hombre como déspota de la naturaleza: como podemos ver hoy en día, la naturaleza siempre pasa la factura. "Se impone, por tanto, una concepción de la naturaleza que no sea un reflejo de nuestros prejuicios, ansiedades y motivaciones; y una concepción del hombre que no lo aleje o lo desgaje del ámbito de la naturaleza, sino que lo considere inserto en la totalidad de la physis, como una pieza más de la realidad; que no lo endiose, que lo haga descender al plano natural y que como consecuencia impida que volvamos a considerar como un coto propio y privado de la humanidad, con derechos absolutos sobre el mismo, lo que no es otra cosa que patrimonio de esa realidad omniabarcante y que se llama naturaleza. $Y$ tal vez sea interesante formarnos una nueva idea sobre qué es la calidad de vida y por extensión, retomar el planteamiento que ya hicieron de un modo tan explícito los filósofos griegos sobre cuál es la auténtica felicidad de los seres humanos. Estas concepciones son las que proporcionarán las guías directrices de la valoración de las tecnologías. Serán los criterios que nos permitan juzgar la legitimidad, si cabe hablar así, de las aplicaciones tecnológicas" ReQuena Manzano, E., Tecnología y valores, en "Anthropos", Revista de documentación científica de la cultura, Barcelona 1989, p. 123: Ésa es la tarea que debemos realizar, esbozando a partir de la sociedad tecnológica un nuevo modo de entender el hombre y de entendernos con la realidad, con una vocación eminentemente operátiva: guiar nuestro desarrollo en la media en que podamos. Para eso necesitamos definir lo que queremos ser, y lo que debemos ser para constituirnos en auténticos seres humanos. 
sólo armados con ellos podremos vencer la dinámica aplastante de la sociedad de consumo. Esos fines deben restaurar la auténtica imagen de lo humano, de la persona abierta a la interrelación creativa con otras personas, objetos y con la naturaleza, a una lógica no de la dominación del medio natural y de los otros hombres, sino de comunicación y valoración de la realidad del otro y de lo otro por sí mismo y no por lo que podamos expoliarle. Se trata de alejarnos lo más posible de la lógica de la posesión. ¿Cómo? Analizando las características antropológicas, epistemológicas, sociales, del hombre tecnológico de nuestros días, sus frustraciones actuales, su relación con la naturaleza, y las necesidades que, a partir de estos factores, se dibujan en la faz oprimida del individuo tecnológico de finales del siglo XX. No nos situamos simplemente en la tradición romántica de la crítica a la tecnología (por encubridora y oscurecedora de los aspectos esenciales de la vida humana), sino que, valorando la tecnología en sí misma, la relacionamos con el hombre y la sociedad que, a la vez que crean, son creados por ella, a fin de conocer cuáles son las necesidades reales del hombre, aquí y ahora, tanto del individuo como de la colectividad, para situarlas como fines de nuestro caminar. A su luz juzgaremos tanto la dinámica tecnológica como la social, la económica, la militar o la política... Es la propia vida la que nos está llamando, la que nos está exigiendo la filosofía... de hoy.

Antonio López PELÁEZ

Madrid

\section{BIBLIOGRAFÍA GENERAL EN CASTELLANO}

Mitcham, C., ¿Qué es la filosofía de la tecnología?, Barcelona, Anthropos 1989.

Mumford, L., El mito de la máquina: I: Las Técnicas y el desarrollo de la humanidad, Buenos Aires, Emecé 1969.

-IDEM, Técnica y civilización, Madrid, Alianza Editorial, 1971.

ORTEGA y GASSET, J., Meditación de la Técnica y otros ensayos sobre la Ciencia y la filosofía, Madrid, Revista de Occidente/Alianza, 1982.

MedinA, M., De la techne a la tecnología, Valencia, Tirant lo Blanch 1985.

WitTGENSTEIN, L. Observaciones sobre los fundamentos de la matemática, Madrid, Alianza, 1987.

Junger, F.G., Perfección y fracaso de la Técnica, Buenos Aires, Sur 1968.

MARCUSE, H., El hombre unidimensional, Barcelona, Ariel 1981.

Habermas, J., Ciencia y Técnica como "Ideología", Madrid, Tecnos, 1986.

SANMARTIN, J., Los nuevos redentores. Reflexiones sobre la ingeniería genética, la sociobiología y el mundo que nos prometen, Barcelona, Anthropos, 1987.

WINNER, L., La ballena y el reactor. Una búsqueda de los límites en la era de la alta tecnología, Barcelona, Gedisa, 1987.

SHALlis, M., El ídolo de sicilio, Barcelona, Salvat, 1986. 